\author{
UNIVERSIDADE DE SÃO PAULO \\ INSTITUTO DE PSICOLOGIA \\ DEPARTAMENTO DE PSICOLOGIA EXPERIMENTAL
}

\title{
ASPECTOS ACÚSTICOS DA DOMESTICAÇÃO: OS CHAMADOS DE CORTE E ALERTA NO PREÁ CAVIA APEREA E NA COBAIA CAVIA PORCELLUS
}

Patrícia Ferreira Monticelli

Dissertação apresentada ao Instituto de Psicologia da Universidade de São Paulo como parte dos requisitos para obtenção do Título de Mestre em Neurociências e Comportamento

Orientador: Prof. Dr. César Ades

São Paulo

2000 


\section{Resumo}

A comparação entre cobaias (Cavia porcellus) e preás (Cavia aperea) fornece dados relevantes para se entender o processo de domesticação (Künzl e Sachser, 1999). No presente trabalho, foram registradas e analisadas sonograficamente (1) a vocalização de alerta, drr, em cobaias e em duas amostras de preás, uma observada em Münster (Alemanha), constituída de animais provenientes da Argentina, e outra constituída de animais provenientes de Itu (São Paulo) e (2) a vocalização de corte, purr, em cobaias e preás de Münster. Encontrou-se diferenças significativas entre $C$. porcellus e ambas as populações de $C$. aperea nos parâmetros temporais do $d r r$ (duração dos pulsos e dos intervalos entre eles e taxa de emissão) assim como diferenças significativas entre as populações de preás de Münster e de Itu (freqüências mínima e máxima da fundamental e freqüência máxima do chamado). No caso do purr, também houve diferenças significativas nos parâmetros temporais das espécies. Estes resultados demonstram a influência da domesticação e de fatores ecotípicos sobre a comunicação vocal e podem, juntamente com a análise sonográfica dos chamados de outras espécies do gênero Cavia, servir para resolução de questões filogenéticas deste grupo. Estudos com playbacks cruzados poderão eventualmente mostrar em que medida as diferenças de vocalização afetam o comportamento social e reprodutivo dos animais. 


\section{ABSTRACT}

Comparision of guinea pigs(Cavia porcellus) and wild cavies (C. aperea) provides privileged models for the understanding of the behavioral effects of domestication (Künzl \& Sachser, 1999). We here present a comparision between alarm ( $d r r)$ and courtship (purr) vocalizations in domestic and wild types of cavies. We recorded and analyzed sonographically such calls in guinea pigs from our laboratory stock and in two samples of wild cavies, one from Münster University (Germany), bred from individuals captured in Argentina, and one from Itu (State of São Paulo). There were significant differences between domestic and both wild cavies samples in the temporal features of the drr (pulse duration, interpulse interval duration and rate of emission) and between the Münster and Itu samples in frequency related features (minimum and maximum freqüencies of the fundamental and maximum frequency of the call). Courtship calls purr of domestic and wild cavies from Münster also differed in temporal acoustical features. Our results show that both domestication and ecotypic factors may influence vocal communication. Playback studies could eventually show to what extent there is interspecific discrimination of the acoustic features of the alarm and courtship calls of cavies. 


\section{DOMESTICAÇÃO E COMUNICAÇÃO VOCAL NA COBAIA}

A cobaia Cavia porcellus é um modelo especialmente interessante para o estudo do processo de domesticação, uma vez que pode ter o seu comportamento comparado, em contextos semelhantes de cativeiro, com o do preá Cavia aperea, que constitui sua forma selvagem, próxima, provavelmente, da estirpe ancestral (Künzl e Sachser, 1999). Uma das características notáveis do comportamento da cobaia é a riqueza da comunicação vocal. Um repertório complexo de vocalizações associa-se a muitos contextos: encontros pacíficos, episódios agonísticos e reprodutivos, interação mãe-filhote, separação de filhotes e exploração do ambiente e de coespecíficos (Arvola, 1974; Berryman, 1976; Coulon, 1982; Tokumaru, Monticelli e Ades, 1996; Monticelli, Tokumaru, Ades, 1997; Monticelli e Ades, 1999), Na presente dissertação, compararemos dois aspectos da comunicação vocal de $C$. porcellus e de $C$. aperea, o drr, uma vocalização emitida em condições de alerta, e o purr, a vocalização de corte do macho.

\section{ASPECTOS DO PROCESSO DE DOMESTICAÇÃo}

A adaptação de uma população selvagem às condições de cativeiro é um processo combinado de mudanças genéticas ao longo de gerações (Connor, 1975; Mundinger, 1995) e de mudanças acarretadas a cada geração 
pela ontogênese do animal e a sua experiência em contextos particulares (Price, 1984; Grandin e Deesing, 1998).

Segundo Hale (1962), Price (1984 e 1998) e Faure e Mills (1998) os mecanismos seletivos atuantes nesse processo seriam: (1) a seleção artificial exercida, intencionalmente ou não, pelo domesticador (por exemplo, a escolha, para reprodução, dos animais mais dóceis); (2) a diminuição da pressão seletiva que atua no ambiente natural (ainda que diminuída, esta pressão pode atuar em determinados setores, como no comportamento reprodutivo); (3) os endocruzamentos e a restrição de trocas gênicas entre populações que favorecem uma ou poucas características, diminuindo a variabilidade gênica da população.

A habituação dos animais à presença do homem, ao longo do processo de domesticação, torna possível uma maior aproximação deste, com diminuição das respostas de fuga e de congelamento e uma propensão menor a reagir defensivamente aos estímulos do meio (camundongos domésticos, Mus musculus: Smith, 1972 e Connor, 1975; ratos de laboratório, Rattus norvegicus: Blanchard et al., 1986; cobaias: Künzl e Sachser, 1999).

Os efeitos da domesticação têm sido avaliados através da comparação, em estudos transversais ou longitudinais, de espécies domesticadas e selvagens, em condições padronizadas. As diferenças encontradas podem ser de caracter (1) morfológico, como o aumento corporal e a perda da plumagem típica em patos domesticados (Miller e Gottlieb, 1981); (2) comportamental, como aquisição, pela linhagem domesticada de porcos, de uma otimização do forrageio (num labirinto com cochos separados por obstáculos, os porcos domesticados passam mais tempo em cada cocho do que os animais cruzados com a espécie selvagem, Gustafsson et al., 1999); e (3) fisiológico, como a antecipação e o aumento da duração do período sensível à socialização primária numa linhagem de raposas altamente selecionadas (Belyaev et al., 1984).

Segundo Hale (1962), os padrões comportamentais (seqüências de movimentos específicos que refletem a organização neuro-motora da espécie) e a organização perceptual, ou seja, a resposta a estímulos desencadeadores 
de comportamentos específicos, são aspectos mais resistentes às mudanças introduzidas durante a domesticação, do que o nível de resposta, ou seja, a freqüência ou intensidade da expressão de um comportamento (Hale, 1962; Ratner e Boice, 1975).

O trabalho de Provine et al. (1984) é um exemplo do quanto podem se manter constantes as características do sistema nervoso central durante o processo de domesticação. Os autores compararam - do dia da eclosão até o $49^{\circ}$ dia de vida - duas linhagens comerciais de galos, produtores de ovos e produtores de carne (Gallus domesticus), ao seu possível ancestral (Gallus gallus) quanto às dimensões corporais, ao desenvolvimento e à capacidade de vôo. Os produtores de carne, que apresentavam índice menor de área de asa/tamanho de corpo, exibiam vôos laterais mais curtos. Quando estimulados a bater asas numa sessão de descida forçada de 1,9 m, controlada pelo experimentador, os animais dos três grupos tinham um desempenho semelhante, uma batida de asa com vigor e simetria bilateral. A redução de desempenho observada na linhagem produtora de carne parece refletir alterações morfológicas e não alterações em estruturas neuro-motoras. Apesar de não emitir, ou de emitir menos freqüentemente, vôos espontâneos, essas aves eram capazes de voar quando forçadas por lançamento, mesmo que de forma mais débil.

A aparente eliminação de um padrão comportamental revela, na maioria dos casos de domesticação, um aumento do limiar a determinados estímulos externos: é o efeito sobre o nível da resposta (Hale, 1962; Ratner e Boice, 1975). Patos domesticados da linhagem Aylesbury apresentam exibições de corte qualitativamente muito semelhantes aos da linhagem selvagem, exceto pela redução da categoria de "captação da atenção" (attention-catching) e pela aparente eliminação da resposta de abaixar a cabeça para a fêmea, após a exibição do "levantamento da cabeça e da cauda" (head-up-tail-up, Desforges e Wood-Gush, 1976).

Os trabalhos de Belayev são exemplos de estudos longitudinais do processo de domesticação. Durante 20 anos, ele selecionou raposas a partir da docilidade, conseguindo padrões de comportamento muito semelhantes aos de 
cães, inclusive o abano de rabo em resposta à aproximação de pessoas. A importância desse estudo foi mostrar que a seleção de um traço pode levar à seleção de características outras, às vezes, inclusive, indesejáveis. As raposas altamente selecionadas tinham, assim, um padrão branco e preto de pele, se reproduziam desordenadamente durante o ano, apresentavam alterações no ciclo estral e níveis aumentados de serotonina, substância conhecida por sua ação inibidora em relação aos comportamentos agressivos (Belyaev, 1979 e Belyaev et al., 1981, em Grandin e Deesing, 1998) e, ainda, antecipavam e aumentavam a duração do período sensível à socialização primária em filhotes (Belyaev et al., 1984).

\section{A COMUNICAÇÃO ACÚSTICA}

A comunicação acústica serve muitas vezes a função de permitir a comunicação em situações nas quais outros meios não podem ser empregados com eficiência. Numa floresta densa ou em contextos de pouca luminosidade, quando é prejudicada a transmissão de sinais olfativos e visuais, e quando se está diante de uma espécie social, pode-se supor que tenha havido um cenário apropriado para a seleção da produção de sinais acústicos (Grier e Burk, 1992; Hauser, 1996).

A categorização do repertório vocal das espécies é um pré-requisito para estudos do papel comportamental e da função do comportamento acústico (Palombit, 1992). Nem sempre é fácil delimitar, com clareza, as categorias vocais; muitos repertórios apresentam uma grande variabilidade, com formas intermediárias, graduadas ou contínuas, entre tipos de vocalizações, e variação nos parâmetros acústicos de um sinal, como freqüência, intensidade e duração; número e estrutura dos elementos, etc. (Grier e Burk, 1992; Newman e Goedking, 1992; Hailman e Ficken, 1996).

As formas de variação podem expressar-se no indivíduo ao longo do tempo na forma de (1) variações internas (caviomorfos, Eisenberg, 1974; Callithrix jacchus, Newman e Goedeking, 1992; Cavia porcellus, Tokumaru, 2000) ou ontogenéticas (Saimiri sciureus: Winter et al., 1973 e Lieblich et al., 
1980; Cercopithecus aethiops: Seyfarth e Cheney, 1986 e Hauser, 1989; Cebuella pygmaea: Elowson, Snowdon e Sweet, 1992; cobaias: Monticelli, Tokumaru e Ades, 1998); ou (2) de diferenças individuais (chimpanzés: Marler e Hobbett 1975; Macaca arctoides: Lillehei e Snowdon 1978; Cebuella pygmaea: Snowdon e Cleveland 1980; Saimiri sciureus: Smith et al. 1982; Cavia porcellus: Monticelli, Tokumaru, e Ades, 1997; focas Halichoerus grypus: McCulloch, Pomeroy e Slater, 1999).

Newman e Goedeking (1992), definem a comunicação como a configuração de uma série de atributos estruturais, potencialmente independentes, cada um com a possibilidade de servir para uma função comunicativa. Essa conceituação permite que se estabeleça uma diferenciação entre a influência de causas internas e causas externas sobre a variabilidade dos sinais. Fatores externos, como os fatores ambientais que facilitam ou dificultam a transmissão do som e a possibilidade de detecção do emissor por predadores, tendem a diminuir a variabilidade estrutural das vocalizações; fatores internos, como a variação do estado motivacional do emissor, tendem a introduzir variabilidade na estabilidade estrutural das vocalizações, ou seja, parâmetros de maior valor na distinção entre indivíduos (por exemplo, freqüência inicial e final e modulação de energia). Há parâmetros que se mantêm ao longo do tempo (por exemplo, ao longo de uma sessão de isolamento social), enquanto outros parâmetros (freqüência média, pico de freqüência e duração) exibem mudanças significativas ao longo do tempo e de acordo com o contexto, não sendo, portanto, adequados como indicadores da individualidade do emissor.

Essa estabilidade de alguns parâmetros nas vocalizações do mesmo indivíduo facilita o reconhecimento individual (ou populacional, como em Cebuella pygmaea: Elowson, Snowdon e Sweet, 1992).

\section{ECOLOGIA E VOCALIZAÇÃo}

As características estruturais dos diferentes chamados estão submetidas à influência do meio em que são emitidos: habitats diferentes variam no nível 
de ruído e no espectro de freqüência de sons presentes no ambiente (Linskens et al., 1976 citado em Brown, Gomes e Waser, 1995) e também no modo como as ondas de som são transmitidas, alteradas e distorcidas (Brown, Gomes e Waser, 1995). Em ambientes abertos (savanas) sons emitidos ao nível do solo recebem maior atenuação (alcançam distâncias menores) do que em ambientes fechados (florestas temperadas e tropicais, Marten e Marler, 1977; Marten e col, 1977).

A freqüência dos chamados e a altura em relação ao solo na qual são emitidos são variáveis importantes na atenuação do som: freqüência superiores a $2.000 \mathrm{~Hz}$ recebem menos atenuação se emitidas numa altura de até 1 metro do solo; acima dessa altura freqüências menores são as que melhor se conservam (Marten e Marler, 1977). Há uma faixa de freqüência entre 500 e $2000 \mathrm{~Hz}$ que recebe menos atenuação no nível do solo (sound window, Morton, 1970, citado em Marten e Marler, 1977).

Brown, Gomes e Waser (1995) compararam a influência de diferentes ambientes (mata atlântica e savana) sobre vocalizações de quatro espécies de macacos (mata: Cercopithecus mitis e Cercocebus albigena; savana: Cercopithecus aethiops e Papio cynocephalus), para verificar a adaptabilidade desses chamados através do grau de distorção do som no habitat natural e em habitat diferente. A distorção do som tem efeitos em domínios de freqüência (causada por variações na freqüência dominante pela atenuação mais rápida de alguns componentes de freqüência do que outros, distorcendo a taxa de amplitude das bandas de freqüência em chamados complexos) e em domínios de tempo (em conseqüência da reverberação). Chamados previamente registrados de cada espécie foram tocados em cada um dos ambientes e regravados a distâncias de 12,5 e 100 metros. Os autores verificaram (1) uma forte distorção do som nos dois habitats já a distância de 12,5 metros, aumentando apenas um pouco a 100 metros (aumento não linear); (2) uma maior distorção dos chamados no ambiente de savana do que na mata; (3) uma menor distorção dos chamados das espécies da floresta nesse ambiente do que nas savanas; (4) uma distorção similar dos chamados das espécies de savana nos dois ambientes. 
Esses resultados mostram que o ambiente da mata é favorável a uma propagação mais fiel do som e que a seleção pode ter atuado de forma diferente nas espécies: nas savanas, a comunicação vocal pode ser otimizada pelo uso de um canal bi-modal de comunicação (visual-auditivo), que não é disponível no ambiente fechado das matas, onde forças seletivas podem ter selecionado, no repertório vocal das espécies, chamados resistentes a distorções (Brown, Gomes e Waser, 1995).

\section{Comunicação VOCAL E FILOGENIA}

A produção sonora, como muitos outros caracteres, é um produto de seleção (Bradbury e Vehrencamp, 1998) e pode servir de ferramenta para a resolução de questões filogenéticas (Vielliard, 1997). Segundo Pinna (1997), não há impedimento, ao contrário pode até haver vantagens, em se traçar um cladograma a partir de caracteres etológicos, tão bons indicadores da história filogenética quanto caracteres morfológicos

Um exemplo do emprego da análise sonográfica para resolução de questões filogenéticas, dado por Vielliard (1997), é o de pica-paus de dois táxons afins (Picumnus cirratus e Picumnus temminckii) com poucas diferenças morfológicas, uma biologia semelhante, distribuição parapátrica, e híbridos naturais na área de contato (segundo Futuyma,1986, as zonas de hibridização são sinais de que o isolamento reprodutivo é apenas parcial e que os táxons estão num estágio intermediário de especiação). Além disso, experiências com playbacks cruzados revelaram reconhecimento entre eles. Estes dados poderiam ter levado a conceber serem esses táxons parte de uma espécie única não fosse pelo fato de que - pela análise sonográfica dos cantos - havia uma diferença significativa no número de notas por frase de cada um deles. Isto significaria, segundo Vielliard (1997), que os táxons estão num nível irreversível de especiação. Esse único caráter bioacústico seria suficiente para manter os indivíduos segregados até que outras pressões adaptativas tornasse cada táxon funcionalmente independente. Enquanto isso não ocorre, para Vielliard, as populações podem ser consideradas "espécies emergentes". 
Segundo Martens (1996), as vocalizações são um poderoso mecanismo de isolamento das espécies; nas aves, a demarcação de território e o reencontro de pares, para o acasalamento, dependem sempre da sinalização sonora. As vocalizações são geralmente constantes em grandes populações, mesmo em regiões geográficas extensas. De acordo com Martens (1996), se as características das vocalizações mudassem, os grupos enfrentariam problemas para se reproduzir e perderiam o seu papel de veículos de genes (gene carrier) da população. Uma vez estabelecido o isolamento reprodutivo, os grupos caminham em direção à formação de duas espécies distintas, independentemente do grau de diferenciação morfológica e genética entre eles (Futuyma, 1986; Kroodsma, Vielliard e Stiles, 1996; Martens, 1996; Vielliard, 1997).

O subgênero Poecile (Parus, Paridae) é um exemplo das informações que se pode obter com a comparação dos chamados do repertório vocal de espécies próximas. O repertório de pelo menos seis espécies de Poecile foi totalmente descrito e as diferenças encontradas quanto ao número, a correspondência de contextos e a qualidade acústica dos chamados separa os grupos de modo idêntico ao modo como os separa a American Ornithologists' Union (AOU): superespécie 1: $P$. carolinensis, $P$. atricapillus e $P$. montanus que são extremamente semelhantes em aparência, habitam florestas decíduas e hibridizam em áreas parapátricas de contato; superespécie 2: $P$. cinctus e $P$. hudsonicus que vivem em florestas de coníferas. $P$. sclateri parece estar entre os dois grupos e também habita florestas de coníferas (Hailman e Ficken, 1996). Estes resultados podem representar homologia ou convergência, sendo necessários, para resolver a questão, dados das outras espécies do gênero Parus e uma comparação com as características dos chamados de outras espécies habitantes de florestas decíduas e de coníferas (Hailman e Ficken, 1996). 


\section{DOMESTICAÇÃO E VOCALIZAÇÃO}

A comunicação vocal, como outros comportamentos, está aberta à pressão seletiva decorrente do processo de domesticação. Os resultados encontrados até agora, em diversas espécies, indicam que há:

(1) uma estabilidade dos componentes perceptuais: mesmo no contexto protegido do cativeiro, perus e frangos domésticos respondem a chamados de alerta de maneira que se assemelha à das respectivas espécies selvagens, com, aparentemente, o mesmo significado comunicativo (Hale, 1962). Patos selvagens (Anas platyrynchos) e patos de linhagens domesticadas (Aylesbury) respondem vocalmente às emissões espontâneas do chamado em "decrescendo" das fêmeas selvagens e domesticadas, e reagem de maneira semelhante a playbacks de chamados de corte (Desforges e Wood-gush, 1976) e a chamados de alarme maternos (apesar de evocar resposta de imobilidade em filhotes dos dois grupos a latência da resposta foi maior na linhagem comercial; Miller e Gottlieb, 1981) obtidos em indivíduos selvagens e domesticados;

(2) uma aparente estabilidade no repertório vocal das espécies. Não há acréscimos ou perdas mas sim substituição de elementos nos chamados. Anas platyrynchos selvagens e da linhagem Aylesbury apresentam a mesma seqüência de movimentos durante a corte, acompanhada de um assobio (grunt-whistle) que perdeu, nos patos da linhagem domesticada, a qualidade acústica típica da espécie (menor modulação de freqüência e intensidade; Desforges e Wood-gush, 1976); 
(3) uma modificação dos limiares de emissão. Ovelhas mães de uma linhagem pouco selecionada vocalizam mais em resposta ao afastamento de seus filhotes (low-pitched bleat ou rumble) do que mães de uma linhagem altamente selecionada; ao contrário, os filhotes da linhagem mais selecionada apresentam maior taxa de vocalização de separação (distress call) do que filhotes menos selecionados (Dwyer et al., 1998); micos-leões nascidos em cativeiro e micos-leões selvagens têm o mesmo repertório vocal, apesar de as chamadas longas serem emitidas menos freqüentemente pelos animais nascidos em cativeiro e de haver variação no contexto de emissão entre ambos os grupos (Ruiz-Miranda et al., 1999). É importante lembrar que os micos-leões do cativeiro certamente não sofreram mudanças extensas que justifiquem pensar que constituem uma estirpe domesticada.

O processo de domesticação também pode ter efeitos sobre os parâmetros acústicos dos chamados. Miller e Gottlieb (1981) compararam a estrutura acústica do chamado de alerta materno emitido por patos selvagens e patos de uma linhagem domesticada (Pekin). Os autores encontraram diferenças estatísticas em dois parâmetros acústicos, a freqüência dominante e a duração da nota. As notas do grupo Pekin apresentaram maior energia em freqüências mais graves, um resultado que os autores atribuem ao aumento da massa corpórea, e são mais breves (houve variabilidade individual e sobreposição desses valores: a linhagem domesticada emitiu notas de duração até maior do que o outro grupo, mas a variação inter-grupo foi maior).

O trabalho de Evans (1993) mostra o papel da freqüência dominante como caracterizadora do chamado de alerta materno: a alteração sintética desse parâmetro diminuiu significativamente a latência de resposta dos filhotes, ou seja, o tempo de imobilidade era menor após playbacks de chamados cuja freqüência dominante havia sido alterada. Apesar de a latência da resposta ser menor frente a playbacks alterados e diminuir proporcionalmente com o grau de alteração desse parâmetro, o fato de os filhotes ainda responderem sugere que outro parâmetro acústico, como a modulação de freqüência e as características temporais, seja também empregado pelos animais no reconhecimento do chamado como sendo o de um coespecífico (Evans, 1993). 


\section{CoBAIAS E PREÁS}

O gênero Cavia, pertencente à família Caviidae (Rodentia), é exclusivo da América do Sul ocorrendo na Colômbia, Equador, Venezuela, Guianas, norte da Argentina, Uruguai, Paraguai e Brasil (Rood, 1972; Wilson e Reeder, 1992).

Há muita polêmica, em torno dos indícios disponíveis (múmias e pinturas em cerâmica) a respeito de quando se teria iniciado o processo de domesticação. Segundo Weir (1974) os Incas teriam iniciado a domesticação desses animais no período de 1.000 a 500 a.C. nas regiões montanhosas da América do Sul, usando os animais como alimento e em cerimônias religiosas. Outros autores consideram que esse processo tenha ocorrido há mais tempo, de 3000 a 6000 anos atrás (Heinemann, 1974; Künzl e Sachser, 1999).

A primeira descrição conhecida da cobaia foi feita por Oviedo em 1547 em Santo Domingo, Peru (provavelmente o animal fora levado para lá pelos espanhóis na invasão de 1532). A cobaia só teria chegado à Europa por volta de 1580, onde é utilizada até hoje como animal de estimação e de laboratório (Weir, 1974).

O estudo de Weir (1974) indica ser Cavia aperea o ancestral direto de Cavia porcellus. A discussão acerca do número de espécies constituintes da subfamílía Caviinae ainda não foi concluída, e Wilson e Reeder (1992) apontam outra espécie como sendo o ancestral da cobaia, Cavia tschudii.

Künzl e Sachser (1999) não têm dúvida quanto ao fato de ser o preá Cavia aperea - o ancestral de Cavia porcellus, porém consideram o período de domesticação muito curto para que tivesse ocorrido uma especiação. Preferem colocar preás e cobaias como uma mesma espécie e usam a denominação Cavia aperea $f$. porcellus para se referir a cobaia doméstica. No presente estudo, consideraremos C. porcellus e $C$. aperea como espécies distintas, como fazem a maioria dos autores que trabalham na área.

Sabendo-se da ligação filogenética destas duas espécies, um estudo comparativo das vocalizações do preá e da cobaia pode servir, como propõe Vielliard (1997) de subsídio para resolver a questão de sistemática. 
O preá é um herbívoro neotropical, freqüente no interior do Estado de São Paulo e em boa parte dos estados brasileiros. De aparência semelhante à da cobaia porém com dimensões um pouco menores e com uma pelagem marrom-acinzentada (Heinemann, 1974), o preá é encontrado nas margens de rios e lagos, em regiões de cerrado e capoeiras (Cassini e Galante, 1992). Costuma buscar refúgio em locais onde a vegetação é alta passando aí a maior parte do tempo, e forrageia em regiões de vegetação mais jovem e mais aberta, mais nutritiva mas com maior risco de predação (Cassini e Galante, 1992). Forragear em grupo parece ser uma adaptação da espécie ao binômio valor nutritivo/risco de predação, na medida em que aumenta a probabilidade de que um ou mais animais do grupo detectem predadores terrestres e alertem os outros através de chamados vocais (Rood, 1972; Cassini e Galante, 1992; Messias, 1995).

C. aperea e C. porcellus apresentam uma hierarquia linear entre machos: um macho dominante tem acesso prioritário às fêmeas do grupo e mantém sua posição social através de encontros agonísticos (Rood, 1972; Sachser, 1986). A espécie selvagem, caracteristicamente mais agressiva, apresenta ainda hierarquia linear entre as fêmeas (Sachser, 1986; Künzl e Sachser, 1999). Há relatos de comportamento agonístico dirigido aos jovens e filhotes de outras fêmeas (Rood, 1972).

Sachser (1986) descreve uma forma de plasticidade social em cobaias que não é observada no preá: quando há crescimento marcado da população a hierarquia linear dá lugar a relações duradouras entre um macho e um certo número de fêmeas. Alguns machos, em posições sociais elevadas, ocupam, junto com "suas" fêmeas (de 1 a 7 fêmeas), um território protegido que não se sobrepõe com o dos outros machos. Machos subordinados não têm acesso às fêmeas, podendo ocupar o território dos machos superiores sem cortejá-las. Nesta organização social, a dominância dos machos tem relação direta com o local dos encontros agonísticos, ao contrário do que se observa em situação de baixa densidade demográfica (Sachser, 1986). Plasticidade social semelhante em direção inversa foi descrita no camundongo selvagem, Mus musculus: sob 
condições semi-naturais a territorialidade (indivíduos defendem seus territórios com agressividade) dá lugar a uma hierarquia de dominância (um indivíduo domina agressivamente os outros) quando o espaço do cativeiro é reduzido (Butler, 1980).

Künzl e Sachser (1999) compararam o comportamento e as respostas endócrinas (atividade do eixo pituitária adreno-cortical - PAC e atividade do sistema simpático adrenomedular - SAM) de grupos familiares (1 macho e duas fêmeas) de cobaias e de preás nascidos em cativeiro, descendentes de indivíduos capturados em estado selvagem em Buenos Aires em 1974). comportamento dos animais foi registrado em vídeo 4 vezes por dia durante 2 semanas, cada sessão com 2 horas e meia de duração. A quantidade de hormônios no soro foi medida a partir de amostras de sangue retiradas de cada macho 2 vezes (dia 1 e dia 2 ) durante esses 14 dias. No primeiro dia o sangue dos machos era coletado 2 vezes, uma antes e uma depois de serem isolados em caixa não familiar.

As observações comportamentais revelaram que o repertório de padrões comportamentais era similar nas duas espécies, não havia ausência ou adição de elementos comportamentais. Diferiu apenas a freqüência de ocorrência dos comportamentos: (1) os preás eram mais agressivos: machos e fêmeas exibiam significativamente mais posturas de curvatura de corpo, investida com a cabeça, ataque, perseguição e mordidas, que representam comportamentos ofensivos agressivos das espécies; (2) as cobaias exibiam significativamente mais comportamentos sociais positivos como o "grooming social" e a "cutucada" (um animal empurra gentilmente o outro com a cabeça), a diferença não foi, contudo, significativa entre as fêmeas de cobaias e de preás; (3) os comportamentos de corte foram mais freqüentes em machos cobaias do que em machos preás mas a diferença estatística só foi encontrada nesta categoria quanto à vocalização que acompanha a corte (rumble, Rood, 1972 e Arvola, 1974 ou purr de Berryman, 1976); (4) preás machos e fêmeas mostraram significativamente mais comportamentos de erguer-se do que as cobaias.

O sentido dessas mudanças no comportamento de cobaias e preás foi o 
mesmo descrito para outras espécies: as espécies domesticadas são menos agressivas, reagem menos a estímulos do meio e são mais tolerantes à coespecíficos (Smith, 1972; Connor, 1975; Blanchard et al., 1986) e exibem com mais freqüência comportamentos de corte (Hale, 1962; Ratner e Boice, 1975; Price, 1984 e 1998).

As diferenças nos níveis endócrinos mostraram o que os autores atestam estar de acordo com a literatura: menor atividade dos sistemas PAC (níveis de cortisol no sangue) e SAM (concentração de adrenalina e noradrenalina) e maiores valores de testosterona na espécie domesticada nos dois dias de coleta de sangue de machos e antes e depois da sessão na caixa não-familiar. O valor inicial da atividade de PAC, no entanto, foi muito próxima para os machos das duas espécies; a comparação de outras espécies domesticadas com seus ancestrais mostra, ao contrário, uma diferença já nos valores iniciais (Künzl e Sachser, 1999).

\section{VOCALIZAÇÃO DE COBAIAS E PREÁS}

A grande variedade de chamados que compõe o repertório vocal da cobaia foi descrita por meio de sonogramas nos trabalhos de Arvola (1974), Eisenberg (1974), Berryman (1976) e Coulon (1982). A metodologia por eles empregada consistiu na manipulação de situações que facilitassem a emissão do maior número possível de vocalizações, havendo identificação do emissor e do contexto específico. As emissões obtidas eram gravadas em áudio e analisadas segundo parâmetros de freqüência, intensidade e tempo. Arvola (1974) utilizou-se ainda de pneumatografias e raio $X$ tirados dos animais no momento das emissões para identificar os chamados como vocais, nasais e naso-orais.

Há entre esses autores diferenças quanto à denominação e ao número de chamados descritos (Tabela 1). As 10 vocalizações identificadas por Berryman (1976) foram aumentadas para 13 na descrição de Coulon (1982) mas os contextos associados às emissões não variam entre os autores, sugerindo que sejam apenas subjetivas as diferenças entre eles na categorização dos tipos de vocalizações. Hailman e Ficken (1996) discutem a 
questão da categorização de tipos vocais.

Para Eisenberg (1974) as diferentes vocalizações da cobaia e de outros histricomorfos (Octodon degus, Myoprocta pratti, Dinomys branickii, dentre outros), são derivações de quatro sílabas básicas que são transformadas ou combinadas de modo diferente de acordo com o estado motivacional do animal e refletem a sua "tendência de ação". Formas intermediárias das sílabas básicas servem de indicadores de excitação do animal, tal como sugerido por Newman e Goedking (1992; hipótese dos atributos dos sinais) e Hailman e Ficken (1996).

Os chamados rítmicos se destacam das outras vocalizações do repertório vocal da cobaia por serem as vocalizações menos ambíguas em relação ao contexto de emissão e estruturalmente menos variáveis. Ao contrário das outras emissões, o drr e o purr (ou rumbles de Rood, 1972 e Arvola, 1974) são frases compostas de unidades idênticas muito breves (pulsos), repetidas em intervalos iguais de tempo (Arvola, 1974; Berryman, 1976; Coulon, 1982). Adotaremos neste trabalho a denominação de Berryman (1976) porque não atribui função aos chamados (designações "funcionais" podem acabar sendo inadequadas, quando se descobre ser outra a função do chamado) e por representar bem, através da onomatopéia, as emissões em questão.

O drr é um sinal de alerta de curta distância (pouca intensidade) facilmente eliciado por estímulos auditivos (Arvola, 1974; Berryman, 1976 e Coulon, 1982), acompanhado de imobilidade (freezing) e postura de vigilância (Eisenberg, 1974; Berryman, 1976). Quando o som é intenso, a fuga pode preceder a vocalização (Coulon, 1982). Segundo Eisenberg (1974), o ritmo e o padrão de distribuição de energia do drr parece análogo ao foot drumming exibido por outros caviomorfos, Dasyprocta e Myoprocta, em situação de alarme.

O purr é o chamado de corte que sempre acompanha a rumba e cujo ritmo de emissão acompanha o ritmo da rumba. Outros chamados podem estar presentes durante a corte, emitidos por fêmea não-receptiva frente às aproximações do macho e por outras fêmeas e filhotes presentes na caixa 
(chutters e whines - Berryman, 1976), pelos machos simultaneamente à emissão purr (grito agudo de excitação - Coulon, 1982) (Tabela 1). Berryman (1976) afirma que fêmeas receptivas também rumbam e emitem purr enquanto exibem posição de lordose e durante monta e cópula.

Sabe-se muito menos a respeito de vocalizações de preás do que a respeito das vocalizações de cobaias. O único trabalho comparativo é o de Rood (1972). Rood (1972) relata emissões vocais de cobaias e preás registradas durante observações dos animais em suas colônias, em interações espontâneas. Suas descrições têm a ver com a qualidade acústica dos sinais, mas não incluem quantificações ou representações sonográficas. Segundo Rood, preás e cobaias emitem uma variedade de notas, entre sons graves e agudos, os bubbly squeaks que, pela descrição do contexto, correspondem ao chut, chutter e whine de Berryman (Tabela 1). As cobaias podem aumentar a freqüência dessas notas gradativamente, passando a emitir assobios, quando em situação de separação social e como resposta condicionada à estímulos relacionados à alimentação. Quando machucados ou assustados, preás e cobaias emitem uma nota muito aguda que soa como um grito, que o autor denomina squeal. Rood parece ter registrado chirps (chamado correspondente ao chirrup ou song, Tabela 1) mais freqüentemente do que os outros autores que estudaram apenas cobaias, mas não deixa claro se era emitido pelas duas espécies. O chirp corresponde a uma série longa (até 15 minutos) de notas repetidas rapidamente, difíceis de serem localizadas, que refletem "ansiedade média" dos animais (como define o autor) e que evocavam respostas de alerta nos outros animais (foram registradas principalmente após aproximação de cães, gatos ou pessoas, tendo possível papel de chamado de alerta).

Rood (1972) também registrou a emissão dos chamados rítmicos de alerta e corte (drr e purr, respectivamente - tabela 1) que chamou de rumbles e que descreveu como "uma série contínua de notas de baixa freqüência com qualidade de burbling ou purring". Segundo ele, a vocalização é emitida por machos sexualmente excitados, durante aproximação ou perseguição da fêmea, acompanhando a rumba (exibição de corte descrita por King, 1956, em cobaias e observada por Messias, 1995 em preás) e pode ser emitido, também, 
por animais de ambos os sexos quando perturbados, indicando ansiedade e com função de alerta entre animais próximos.

TABELA 1. Chamados vocais de cobaias segundo as denominações de Berryman (1976) e Coulon (1982), e os contextos de emissão.

\begin{tabular}{|l|l|l|}
\hline Berryman & \multicolumn{1}{|c|}{ Coulon } & \multicolumn{1}{c|}{ Contextos de emissão } \\
\hline chut & grito de coesão social & separação, exploração, interações mãe/filhote e sexuais \\
\hline chutter & grito de contato social & separação, encontros sexuais e agonísticos \\
\hline whine & grito de perturbação & persistência dos mesmos contextos do chutter \\
\hline whistle & grito de procura e assobio de apelo & separação e antecipação da chegada do alimento \\
\hline tweet & grito do jovem sendo limpo & filhote tendo sua região ano-genital lambida pela mãe \\
\hline squeal & grito de estresse & imobilização súbita, machucado ou golpe \\
\hline & grito agudo de dor & \\
\hline scream & grito de estresse & imobilização súbita, machucado ou golpe \\
\hline & grito agudo de dor & \\
\hline drr & grito rítmico de alerta ao som & resposta de alerta a estímulos do meio \\
\hline purr & grito rítmico de amamentação & busca da teta, filhotes machos próximo às fêmeas \\
\hline & grito rítmico sexual & exibições de corte \\
\hline chirrup & song & ocorrência rara, alerta à modificações no meio \\
\hline
\end{tabular}

Segundo Arvola (1974), os chamados de alerta e corte diferem quanto à duração da frase (purr é mais longo e ocorre, em geral, em surtos com várias frases de durações variadas; Arvola afirma que o drr não é repetido sem recorrência do estímulo eliciador), à ritmicidade (menor no purr) e à faixa de freqüência da fundamental (o purr é mais grave).

Nosso objetivo foi comparar aspectos acústicos do drr e do purr emitidos por C. porcellus e por duas populações de $C$. aperea (preás capturados na Argentina e preás capturados no Brasil). 
MÉTODO

\section{SUJEITOS EXPERIMENTAIS}

COBAIAS.

Utilizamos as cobaias da criação do biotério do Departamento de Psicologia Experimental da USP. Organizamos os animais em colônias de 2 ou 3 adultos (consideramos um animal adulto quando tem mais de 3 meses) em caixas plásticas de $58 \times 60 \times 100 \mathrm{~cm}$ em duas salas do biotério, com alimento (ração para coelho e verduras) e água ad lib.

A composição das colônias era a seguinte: colônias 1 a 5 , cada uma com um macho e duas fêmeas (família); colônias 6 e 7, compostas de fêmeas adultas (3 fêmeas grávidas na colônia 7); colônia 8 , dois machos irmãos reunidos quando tinham 1 mês de vida; colônias 9 e 10, compostas de machos nascidos em nosso biotério mas que não fizeram parte destas colônias (Tabela 2). Houve 6 ninhadas nascidas entre maio e junho na colônia 2 (ninhada da F15), colônia 4 (ninhada da F9 e da F16) e colônia 7 (as 3 fêmeas tiveram ninhada).

PREÁS.

Foram utilizados preás de duas procedências: uma amostra de animais observada em Münster, na Alemanha, e outra de animais capturados em Itu, SP. 
Münster: os preás deste grupo correspondem a gerações de animais capturados há 5 anos em Buenos Aires, Argentina, e mantidos no laboratório do Professor Norbert Sachser no Instituto de Neurociências e Comportamento (Institut für Neuro- und Verhaltensbiologie) da Universidade de Münster, Alemanha. Os animais usados como sujeitos estão indicados na Tabela 2, não sendo indicadas as ninhadas (houve um fluxo intenso de nascimento e retirada de filhotes por grupo). Os animais eram mantidos em caixas de madeira de dimensões aproximadas de $1 \times 1 \times 1 \mathrm{~m}$ em duas salas do biotério daquele laboratório com suprimento de água, ração e aveia ad lib e semanalmente feno. As colônias 11 e 12 eram mantidas em cercados separados em um cativeiro externo com uma área coberta (aproximadamente $6 \mathrm{~m}^{2}$ ) e uma área fechada apenas com tela (aproximadamente $8 \mathrm{~m}^{2}$ ).

ITU: capturamos preás numa propriedade rural com pastagens e brejo (Figura 1), no município de Itu, São Paulo (23⒖51' S $47^{\circ} 17.57^{\prime}$ O). Num primeiro período, agosto a novembro de 1998, utilizamos armadilhas caseiras do tipo "pitfall" construídas com lata e madeira (Figura 2.a), e armadilhas de ferro com portas de guilhotina (Figura 2.b). Posteriormente, de junho a agosto de 1999, substituímos as armadilhas caseiras pela Hanavahart modelo 1025-1 (com portas tipo guilhotina). 


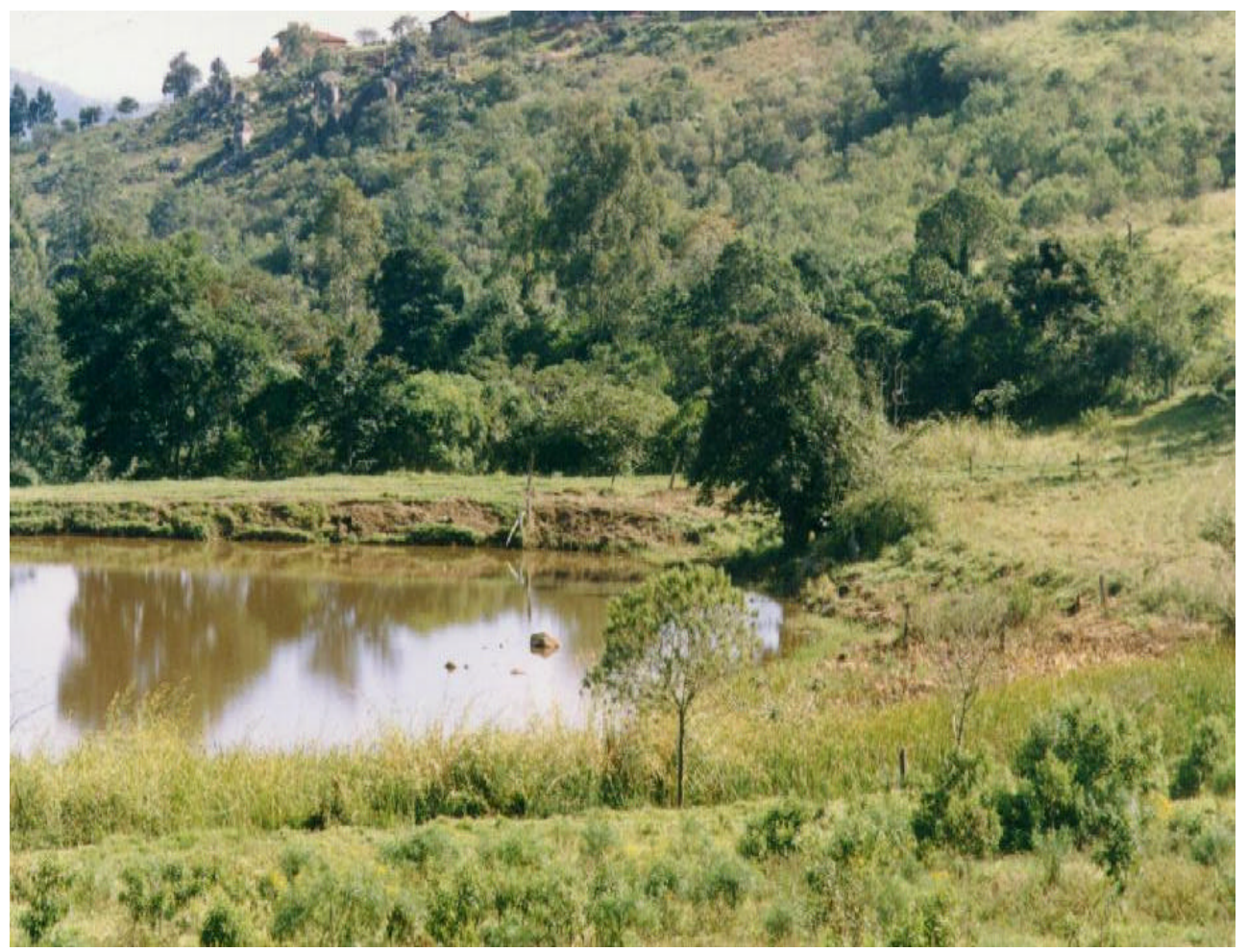

FiguRA 1. Propriedade rural em Itu onde foram colocadas as armadilhas para captura de preás. A área é formada de um lago beirado por brejo e área de pastagem. 



FIgURA 2. Armadilhas confeccionadas para captura de preás. (A) tipo "pitfall" construída com lata: a tampa está aberta em posição vertical ao solo; (B) tipo "live trap" com duas portas laterais tipo guilhotina que se fecham quando o animal toca um dispositivo no centro da armadilha. 
Organizamos os animais em 5 colônias (conforme a Tabela 2) que mantivemos num cativeiro externo construído em alvenaria numa propriedade particular próxima ao local de captura (dimensões: $3 \times 2 \times 1 \mathrm{~m}$ ). Os animais foram inicialmente alimentados com capim e depois passaram a receber ração de coelho e verduras. A fêmea I1F2 (Tabela 2) foi capturada grávida e pariu 2 filhotes no início das observações. As fêmeas dos grupos 3 e 4 pariram 3 gerações e os filhotes, com 2 meses, foram retirados dos grupos formando grupos novos (grupo 15) ou foram levados para o biotério do Departamento de Psicologia Experimental, onde foram utilizados como sujeitos desta pesquisa (I3M6 e 14M7).

TABela 2. Composição das colônias de cobaias, preás do cativeiro de Münster e preás de Itu. $\mathrm{O}$ sexo dos animais está indicado pelas letras $\mathrm{M}$ (macho) e $F$ (fêmea). Nos dois grupos de preás o primeiro número de cada animal representa a sua linhagem.

\begin{tabular}{|c|c|c|c|}
\hline & Cobaias & Preás Münster & Preás Itu \\
\hline 1 & $\mathrm{M} 1, \mathrm{~F} 17, \mathrm{~F} 23$ & A1M17,A1F44,A1F54 & I1M1,I1F2,I1F3 \\
\hline 2 & M11,F15 & A1M19,A1F53,A1F58 & I2M2,I2F1 \\
\hline 3 & $\mathrm{M} 9, \mathrm{~F} 2, \mathrm{~F} 13$ & A3M23,A3F31,A3F32 & I3M3,I3F4 \\
\hline 4 & M8,F9,F16 & A4M18,A4F16,A4F22 & I4M4,14F5 \\
\hline 5 & $\mathrm{~F} 7, \mathrm{~F} 18, \mathrm{~F} 20$ & A4M22,A4F15,A4F20 & I5M5,I5F6 \\
\hline 6 & $\mathrm{~F} 1, \mathrm{~F} 10, \mathrm{~F} 21$ & A5M9,A5F2,A5F20 & I3M6 \\
\hline 7 & M12,M13 & A5M12,A5F1 & 14M7 \\
\hline 8 & M9b & A3M24,A3F38 & \\
\hline 9 & M7 & A1M16,A1F41 & \\
\hline 10 & M Lestat & A5M11,A5F11 & \\
\hline \multirow[t]{2}{*}{11} & & A6M1,A6F8,A6F18,A6F27 & \\
\hline & & A6F32,A6F34,A6F35 & \\
\hline \multirow[t]{2}{*}{12} & & A3M1,A3F20,A3F22, & \\
\hline & & A3F23,A3F28,A3F29 & \\
\hline
\end{tabular}




\section{Procedimento}

Como os contextos de emissão dos chamados rítmicos são muito específicos (alerta e corte - Arvola, 1974; Eisenberg, 1974; Berryman, 1976; Coulon, 1982) nossa coleta de dados com cada grupo (cobaias, preás do cativeiro de Itu e preás do cativeiro de Münster) baseou-se em (1) sessões de gravação das colônias (biotérios e cativeiros externos), (2) sessões experimentais de formação de pares não-familiares (casais) conduzidas em sala-teste com caixa-teste e (3) manipulação dos animais individualmente e nas colônias.

A metodologia utilizada para os 3 grupos de animais foi semelhante, apesar de ter ocorrido em locais e em épocas diferentes. As salas experimentais ficavam muito próximas dos biotérios, as caixas experimentais eram de madeira sem fundo (para reduzir ruído das patas dos animais) com dimensões $49 \times 47 \times 27 \mathrm{~cm}$ e não continham nem alimento nem água. $O$ transporte dos animais era feito em caixas pequenas de madeira ou plástico, apenas por ocasião das sessões experimentais. Em Itu, a distância entre o cativeiro externo e a sala experimental era maior e o transporte dos animais durava em média um minuto. Nos dois grupos de preás, as caixas experimentais recebiam uma tampa de tela para evitar fuga dos animais (segundo estimativa de Rood, 1972, preás podem saltar até um metro; erguemse muito freqüentemente nas paredes das caixas).

\section{SITUAÇÕES DE REGISTRO}

Colônias. Fizemos pelo menos 3 observações em cada colônia dos 3 grupos de animais. Observações não sistemáticas eram feitas quando ocorriam nascimentos, cio de uma fêmea acompanhada de macho, disputa de posição hierárquica (jovens machos x pais) e manutenção das caixas (limpeza e troca de serragem). As gravações das colônias duravam em média 30 minutos mas podiam levar mais de uma hora dependendo da variabilidade de interações na caixa.

Formação de pares. Machos e fêmeas não-familiares eram transportados para a sala experimental e eram colocados ao mesmo tempo na 
caixa experimental com os equipamentos de registro já ligados. As sessões duravam de 10 a 15 minutos. Em Münster podiam chegar a durar 30 minutos porque os animais levavam mais tempo para iniciar as interações. Algumas sessões foram interrompidas quando os animais entraram em confronto ou quando não havia mudança nas categorias de interação.

Manipulação. Duas situações que facilitam a emissão do chamado de alerta (drr) em cobaias são ruídos externos breves e repentinos e a manipulação direta dos animais pelo ser humano. Neste caso é comum também cobaias emitirem o chamado de corte, purr, ou uma variante desse chamado. Animais dos três grupos (cobaias, preás de Münster e preás de Itu) foram submetidos a sessões de (1) manipulação direta: retirávamos um animal de sua caixa e passávamos os dedos persistentemente pela superfície do dorso e barriga, no sentido contrário ao nascimento dos pêlos; e (2) de apresentação de estímulo sonoro: entrávamos na sala dos animais e estalávamos os dedos, produzindo um barulho breve e intenso.

\section{EQUIPAMENTO DE REGISTRO}

A cada sessão registrávamos, em vídeo e áudio, as interações sociais e as vocalizações a elas associadas, procurando sempre que possível identificar o emissor e a reação dos outros indivíduos. Para a gravação das vocalizações utilizamos um gravador Sony Dat TCD-D8, e um microfone unidirecional Sennheiser ME 66, colocados no local da gravação (biotérios, cativeiros externos ou salas experimentais) posicionando o microfone na altura da parede da caixa, em ângulo de $45^{\circ}$ com ela (nos biotérios de Münster e no cativeiro de Itu o microfone ficava a aproximadamente $50 \mathrm{~cm}$ do solo e perpendicular a ele).

Utilizamos inicialmente uma filmadora compacta VHS JVC que substituímos depois por uma filmadora CCD-TR36 - Hi8; a filmadora era colocada sobre as caixas, a uma distância suficiente para focalizar toda a colônia. 
ANÁLISE SONOGRÁFICA

Para a análise das vocalizações, utilizamos 0 software Avisoft SASLabPro 3.4. Através desse programa geramos sonogramas que compreendiam a faixa de freqüência entre 0 e $2,5 \mathrm{kHz}$, dando uma margem maior ao limite máximo de freqüência atingido por esse chamado $(1,7 \mathrm{kHz}$ segundo Berryman, 1976), com uma boa resolução de freqüência (utilizamos resolução de $27 \mathrm{~Hz}$ - FFT $256 \mathrm{~Hz}$, frame 100\%, window: hamming) sem perder muito em resolução de tempo (utilizamos resolução de 1,45 ms; overlap: 98.43\% - quanto maior a resolução de freqüência menor a resolução de tempo e vice-versa; Clements, 1998). Das vocalizações obtidas selecionamos as que apresentavam melhores condições de análise, isto é, menor nível de ruído de fundo, sem sobreposição com outras vocalizações e cujo emissor tivesse sido identificado. Foi muito difícil identificarmos o emissor do chamado drr: É emitido com a boca fechada e o único sinal visível durante a emissão é um leve tremor na cabeça e orelhas. Nos preás esse tremor parece ainda mais sutil do que na cobaia e no caso dos animais de Itu, na maioria dos casos, não foi possível identificar o emissor em sessões de formação de pares, motivo pelo qual tivemos que considerar o casal conjuntamente, como um único sujeito.

As figuras 3 e 4 são representações gráficas dos chamados drr e purr, com identificação dos parâmetros acústicos: chamamos de pulso a menor unidade do chamado, que se repete em intervalos de tempo constituindo uma frase; cada pulso dos chamados ocupa uma faixa de freqüência inferior, que chamamos de fundamental, podendo apresentar outros elementos em freqüência acima dessa faixa (freqüência máxima). Quando outros elementos de freqüência não estão presentes, a freqüência máxima da fundamental corresponde a freqüência máxima do chamado. Em cada figura, o gráfico 3 apresenta no eixo $x$ valores de amplitude em $\mathrm{dB}$ (amplitude relativa ao arquivo de som, no qual o ponto de maior energia é considerado zero, e os outros valores são relativos a ele) e no eixo y a freqüência em kHz. Através desse gráfico podemos identificar a freqüência de maior energia do chamado, freqüência dominante. Chamamos de taxa da emissão ('taxa') o que Arvola (1974) e Coulon (1982) denominaram ritmo (número de pulsos por segundo). $O$ 
purr, em geral, não é uma emissão isolada, ocorrendo em surtos (conjunto de frases separadas por intervalo de até 0,6 segundos) como no exemplo da figura 4, na qual distinguimos 3 frases, sendo que a $2^{\mathrm{a}}$ e a $3^{\mathrm{a}}$ constituem um surto.

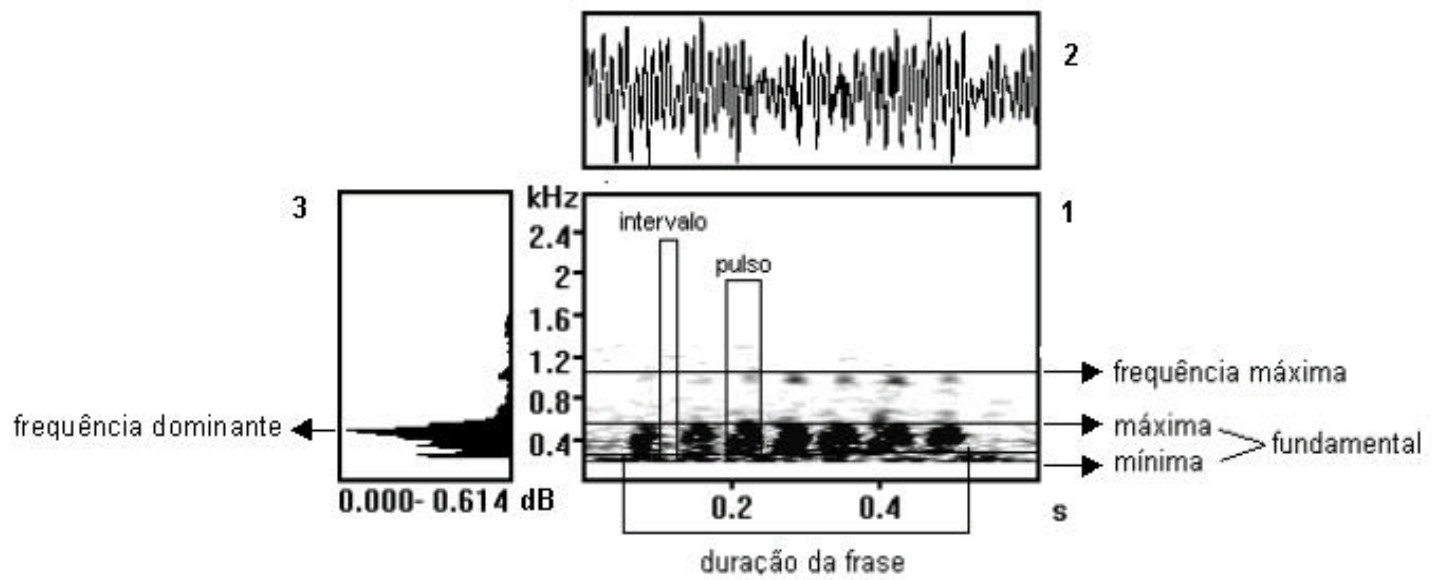

B

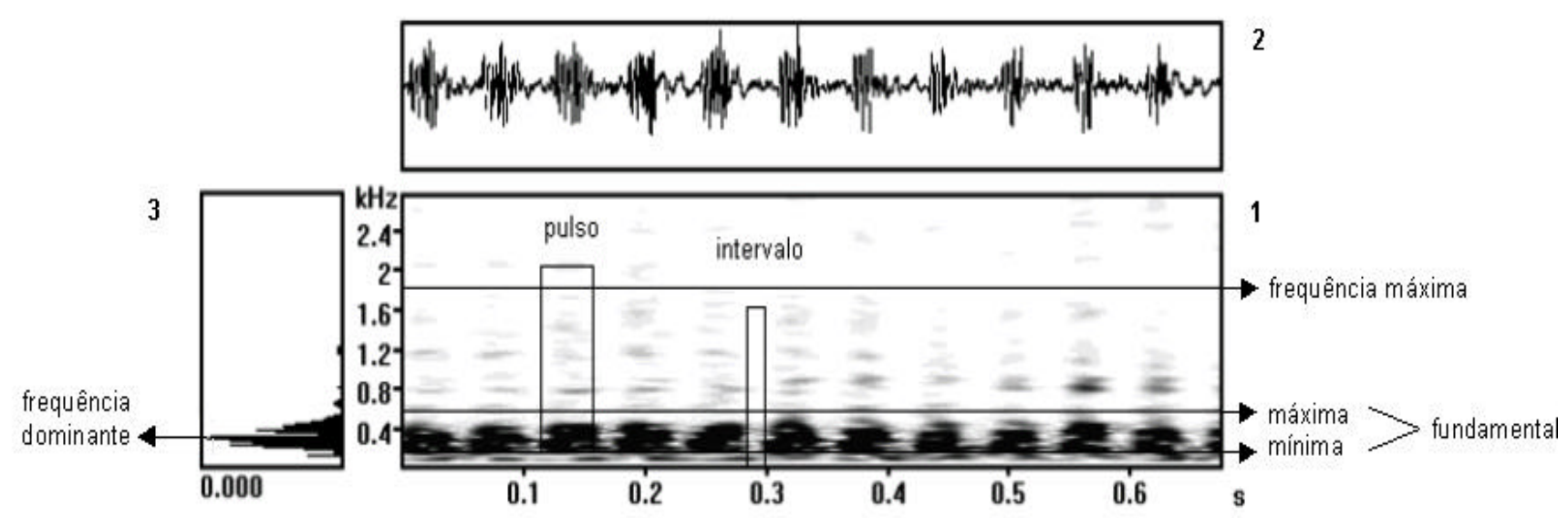

FIGURA 3. Sonogramas representativos das emissões $\operatorname{drr}(\mathrm{A})$ e purr (B). 1. espectro de freqüência: identificação de pulsos (menor unidade do sinal), intervalos entre eles, a faixa (freqüência mínima e máxima) da fundamental, e freqüência máxima do chamado. 2. onda de som (ditribuição temporal da energia). 3. espectro de freqüência por amplitude: identificação da freqüência de maior energia do chamado (valor mais próximo de $0 \mathrm{~dB}$ ). 




FIgURA 4. Sonograma de um surto de purr emitido por uma cobaia macho durante cortejo da fêmea. As frases 2 e 3 constituem um surto (intervalo entre frases de até 0,6 s). O episódio total de corte teve duração de 6,5 s (início em 0,2 e fim em 6,8 s aproximadamente). 
Tomamos, as seguintes medidas em cada chamado:

Drr. número de pulsos, duração dos pulsos, duração dos intervalos entre pulsos, duração da frase, taxa da emissão, freqüência mínima e freqüência máxima da faixa da fundamental, número de elementos de freqüência acima da faixa da fundamental, freqüência máxima e freqüência dominante.

Purr: duração do surto, número de frases por surto, duração da frase (no caso dos surtos medimos apenas a frase de maior duração), duração dos intervalos entre frases, duração dos pulsos, duração dos intervalos entre pulsos, taxa da emissão, freqüência mínima e freqüência máxima da faixa da fundamental, freqüência máxima e freqüência dominante.

\section{ANÁLISE DOS DADOS}

\section{Análise descritiva.}

Tomamos como dado básico para a análise a média de cinco registros de cada parâmetro acústico, em cada animal. Como a variação intra-individual foi pequena, consideramos que a média fosse bem representativa. No caso do $d r r$, foram usadas as seguintes amostras de sujeitos: cobaias $n=14$, Itu $n=7$ e Münster $n=13$. No caso do purr: o tamanho das amostras foi: cobaias $n=8$, Itu $n=2$ e Münster $n=8$. $O$ tamanho reduzido da amostra de Itu fez com que não a incluíssemos nas análises quantitativas do purr .

Para verificar se havia um padrão na distribuição de energia dentro da frase drr (ou seja, modulação de energia ao longo da frase) tornamos os dados de intensidade de cada frase comparáveis, dividindo todos os valores de intensidade da frase (um valor para cada pulso) pelo maior valor deles. Dessa forma obtivemos valores de 1 a 2 (os valores de intensidade relativos a cada arquivo de som eram valores negativos já que o ponto de maior energia era zero), onde 1 representava o pulso de maior energia da frase.

Análise de variância.

A diferença entre grupos (Cobaias x Preás de Münster x Preás de Itu) nos parâmetros do drr foi testada através de uma análise de variância univariada (SPSS 7.5), com $p=0,01$, e os contrastes dois a dois através do 
teste post hoc de Tukey. No caso do purr, foi usada apenas a análise de variância, uma vez que os dados disponíveis para análise eram apenas de Cobaias e preás de Münster.

Para verificar se havia diferença entre drrs emitidos por machos e fêmeas (Cobaias x preás de Münster), utilizamos uma análise de variância (SPSS 7.5) com dois fatores, sexo $\times$ grupo. Não foram usados dados do grupo de Itu uma vez que, como indicado mais acima, não era possível identificar o emissor.

\section{Análise discriminante.}

Utilizamos as médias dos parâmetros acústicos do drr e do purr, emitidos por animais de cada grupo, como variáveis para a análise discriminante (SPSS 7.5).

A análise discriminante tem sido usada em trabalhos nos quais se pretende classificar indivíduos em grupos utilizando-se como variáveis para essa classificação os parâmetros acústicos de seus chamados (Smith, 1982; Newman e Goedeking, 1992; McCulloch e col., 1999). Num trabalho anterior (Monticelli, Tokumaru e Ades, 1998), encontramos assinatura vocal no assobio de separação de filhotes de cobaias, mas o que diferenciou os filhotes foi um conjunto de variáveis; os parâmetros diferenciavam de forma diferente os sujeitos e, em uma comparação entre os pares de indivíduos, alguns pares foram discriminados por um número maior de parâmetros acústicos que outros. Os filhotes apresentavam um padrão individual e não diferenças em aspectos particulares da nota. A análise discriminante leva em consideração o padrão geral para classificar e não só diferenciar indivíduos.

Por meio desta análise cada frase (Drr: cobaias, $n=14$, preás de Münster, $n=13$ e preás de Itu, $n=7$; Purr: Münster $n=8$ e cobaias $n=8$ ) é atribuída a um sujeito (cada grupo era um sujeito) considerando-se em conjunto os valores de seus parâmetros acústicos (análise multivariada). Utilizamos o método stepwise com dois critérios para determinar que variáveis (parâmetros) entrariam na análise e em que ordem. Primeiro, valores de $\mathrm{F}$ univariados e lambdas de Wilks foram calculados para cada parâmetro antes 
da primeira etapa (first step). Após cada etapa, onde um parâmetro podia entrar ou sair da análise, estes valores foram recalculados. Para que um parâmetro entrasse ( $F$ to enter) e fosse mantido ( $F$ to remove) ele deveria apresentar probabilidade de $F$ menor ou igual a 0,01 , valor que determinava, segundo nosso critério pré-estabelecido, que a variável possuia variância significativa entre os grupos. Dada esta probabilidade, a ordem na qual cada parâmetro entraria na análise era determinada pelo efeito sobre o lambda de Wilks. O primeiro parâmetro a entrar é o que apresenta o menor lambda; dai por diante os parâmetros são escolhidos quando sua entrada diminui o valor do lambda anterior.

A análise cria funções discriminantes (baseado no coeficiente de Fisher) que são usadas para classificar as frases. O número máximo de funções é igual ao número de sujeitos menos 1 (neste caso 2 funções, já que estamos comparando 3 grupos). A primeira função é sempre a que apresenta o maior poder discriminativo enquanto a última apresenta o menor; uma indicação da força discriminativa de cada função é dada pela porcentagem de variância atribuída a ela. A contribuição relativa de cada parâmetro para cada função, é dada pelo valor absoluto de seu coeficiente. 


\section{3}

DRR: UM CHAMADO DE ALERTA

O drr é um sinal de alarme de curta distância (pouca intensidade) emitido pela cobaia doméstica, facilmente eliciado por estímulos auditivos (Arvola, 1974; Berryman, 1976 e Coulon, 1982) e acompanhado de imobilidade (freezing) e postura de vigilância (Eisenberg, 1974; Berryman, 1976). Se o som for intenso a fuga pode preceder a vocalização (Coulon, 1982).

Berryman (1976) afirma que o drr pode ser emitido como resposta a qualquer tipo de mudança no ambiente, enquanto Arvola (1974) e Coulon (1982) restringem estes estímulos aos auditivos, descartando esta emissão como resposta a estímulos visuais.

Sons instantâneos de alta freqüência, mesmo se de baixa intensidade (por exemplo, molho de chaves balançado ou jogado no chão, papel sendo rasgado) são melhores eliciadores de drr na cobaia do que sons de baixa freqüência, sendo maior a gama de estímulos aos quais o animal reage durante a noite, quando os ruídos de fundo do ambiente são menores (Arvola, 1974).

O caráter de "alerta" do drr é reconhecido por vários autores. Arvola (1974) cita trabalhos nos quais esta vocalização também é denominada rumble (Kunkel e Kunkel, 1964) e nos quais se apontam como condições propícias para seu aparecimento, estímulos sonoros perturbadores (Tembrock, 1959) ou um estado de alarme leve dos animais (Koponen, 1962).

Cobaias de ambos os sexos e em todos as idades (a partir de 6 dias de vida segundo Coulon, 1982) emitem essa vocalização. Em geral, quando um indivíduo a produz, outros também se põem a produzí-la. As vocalizações induzidas podem tanto ser uma resposta ao estímulo ao qual reagiu o primeiro 
animal, como respostas à própria emissão deste (Arvola, 1974; Coulon, 1982). Sexo, idade e tamanho corporal não modificam a estrutura do drr (Arvola, 1974).

INFORMAÇÕES PRÉVIAS A RESPEITO DA ESTRUTURA ACÚSTICA DO DRR DA COBAIA

Arvola (1974) caracteriza o drr como uma emissão nasal. Uma radiografia das cobaias, durante a emissão, mostra apenas movimentos sutis das partes laterais da região posterior da língua, sem abertura ou fechamento de passagens de ar. As cavidades ressonantes são a cavidade nasal e a traquéia. Uma anestesia da língua não impede cobaias de produzir o drr.

O drr foi descrito como um chamado rítmico não modulado (Arvola descreve uma flutuação de freqüência de apenas $100 \mathrm{~Hz}$, podendo ser ascendente, descendente ou um pico no meio do chamado), composto de unidades idênticas muito breves (notas ou pulsos) repetidas em intervalos iguais, extremamente curtos, o conjunto das quais forma uma frase (Berryman, 1976; Coulon, 1982). A duração dos pulsos aumenta geralmente do meio para o final da frase enquanto diminui a intensidade (Arvola, 1974).

O drr tem qualidade sonora grave e pouca intensidade, passando as vezes despercebido ao ouvido humano ou camuflado por ruídos do ambiente. No sonograma, o drr aparece como uma faixa de freqüência que os autores chamam de faixa da fundamental, na qual não é possível distinguir elementos de freqüência. Acima dessa faixa podem aparecer harmônicos (Berryman, 1976). A Tabela 3 mostra os parâmetros acústicos de drrs emitidos por cobaias, segundo Arvola (1974), Berryman (1976) e Coulon (1982). Os valores apresentados correspondem aos limites máximos e mínimos obtidos para cada parâmetro. Os valores colocados entre parênteses em algumas células representam os valores mais comumente obtidos. 
TABela 3. Parâmetros acústicos do chamado de alerta (drr) de cobaias

\begin{tabular}{|l|c|c|c|}
\hline & Berryman & Arvola & Coulon \\
\hline ritmo (pulsos/s) & & $10-20$ & $10-16$ \\
\hline duração dos pulsos (s) & $0,025-0,04$ & $0,02-0,06$ & $0,015-0,03$ \\
\hline intervalo entre pulsos (s) & $0,025-0,06$ & $0,06-0,1$ & \\
\hline número de pulsos & $5-15$ & $4-11$ & $4-14(6-9)$ \\
\hline duração da frase (s) & $0,2-0,8$ & $0,2-0,9(0,3-0,6)$ & $0,2-0,75$ \\
\hline faixa de freqüência (Hz) & $200(1.700)$ & $250-550$ & $220-600$ \\
\hline número de harmônicos & $1-4$ & $1-2$ & \\
\hline (Berryman; 1976; Arvola, 1974; Coulon, 1982). A faixa de freqüência
\end{tabular}
representada é a faixa da fundamental. $O$ valor em parênteses representa a freqüência máxima (quando existem harmônicos).

\section{REsultados}

\section{ANÁLISE DESCRITIVA}

A Figura 5 apresenta amostras de sonogramas de drrs emitidos por cobaias, preás de Münster e preás de Itu, as Figuras 6 e 7 os valores médios dos parâmetros nos três grupos de animais e a Tabela 4 os valores mínimo e máximo (limites) e o desvio padrão (dp) de cada parâmetro. 


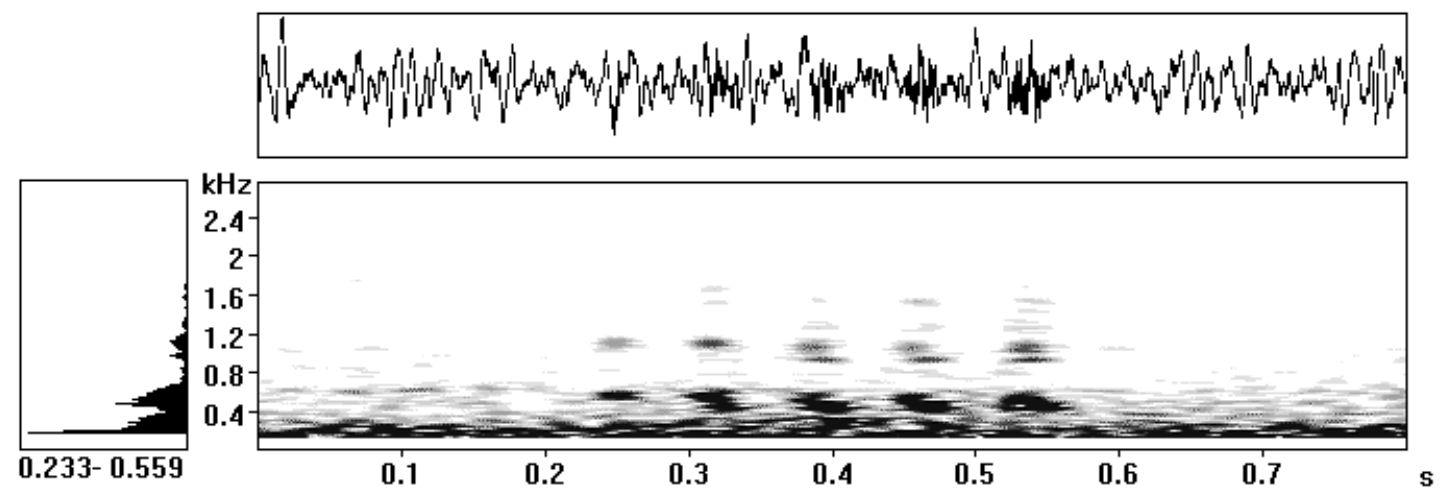

B



C



FIGURA 5. Sonogramas representativos do chamado de alerta emitido por $(A)$ cobaia: frase com $0,32 \mathrm{~s}, 5$ pulsos e freqüência dominante em $0,43 \mathrm{kHz}$; $(B)$ preá de Münster: 
um nota de chut antecede o $d r r$ de $0,16 \mathrm{~s}$, com 4 pulsos e freqüência dominante em $0,40 \mathrm{kHz}$, e (C) preás de Itu: frase com 8 pulsos, duração 0,32 s e freqüência dominante em torno de $0,2 \mathrm{kHz}$. Nos 3 sonogramas a freqüência de maior intensidade abaixo da faixa da fundamental de cada chamado refere-se ruído de fundo. 

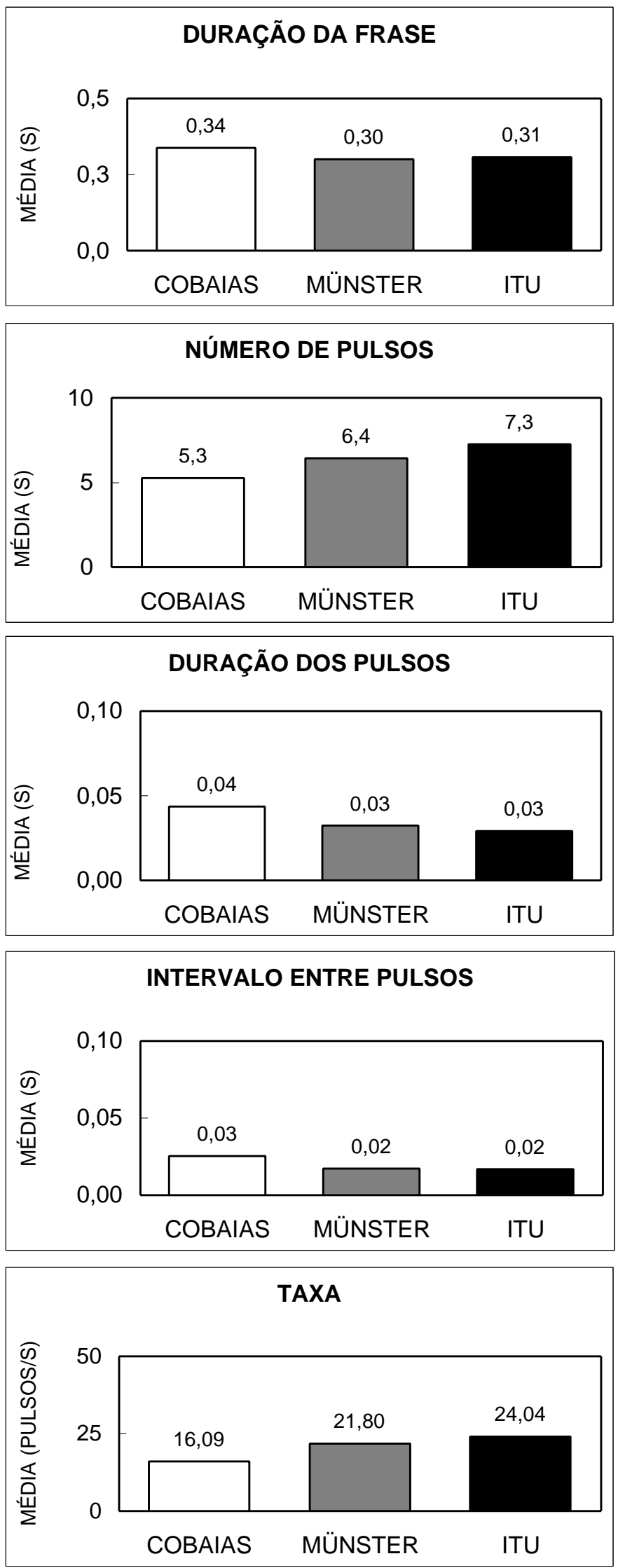

FiguRA 6. Valores médios dos 5 parâmetros acústicos de carater temporal do drr emitido por cobaias, preás de Münster e preás de Itu. 



FIgURA 7. Valores médios dos 5 parâmetros acústicos relativos a freqüência do $d r r$ de cobaias, preás de Münster, preás de Itu. 
TABELA 4. Valores mínimo e máximo (limites) e desvio padrão (dp) de cada parâmetro 
acústico dos chamados de alerta ( $d r r)$ emitidos por cobaias e preás de Münster e ltu.

\begin{tabular}{|l|r|c|r|r|r|r|}
\hline \multirow{2}{*}{$\begin{array}{c}\text { Parâmetros } \\
\text { acústicos }\end{array}$} & \multicolumn{2}{c|}{ Cobaias } & \multicolumn{2}{c|}{ Münster } & \multicolumn{2}{c|}{ Itu } \\
\cline { 2 - 7 } & min-max & dp & min-max & dp & min-max & dp \\
\hline duração da frase (s) & $0,20-0,54$ & 0,10 & $0,22-0,40$ & 0,05 & $0,24-0,39$ & 0,06 \\
\hline número de pulsos & $3-8$ & 1,39 & $5-8$ & 1,00 & $5-11$ & 1,87 \\
\hline duração dos pulsos (s) & $0,03-0,05$ & 0,01 & $0,03-0,04$ & 0,00 & $0,02-0,03$ & 0,00 \\
\hline intervalo entre pulsos (s) & $0,02-0,04$ & 0,01 & $0,01-0,02$ & 0,00 & $0,01-0,02$ & 0,00 \\
\hline taxa (pulso/s) & $13,24-21,85$ & 2,24 & $19-25$ & 1,69 & $21-28$ & 2,04 \\
\hline freqüência mínima da fundamental (kHz) & $0,12-0,28$ & 0,04 & $0,11-0,26$ & 0,04 & $0,05-0,10$ & 0,02 \\
\hline freqüência máxima da fundamental (kHz) & $0,22-0,48$ & 0,06 & $0,26-0,39$ & 0,04 & $0,09-0,17$ & 0,03 \\
\hline número de elementos de freqüência & $0-5$ & 1,66 & $1-10$ & 2,13 & $3-6$ & 0,99 \\
\hline freqüência máxima (kHz) & $0,39-1,67$ & 0,40 & $0,46-2,17$ & 0,46 & $0,47-1,13$ & 0,22 \\
\hline freqüência dominante $(\mathrm{kHz})$ & $0,18-0,39$ & 0,06 & $0,15-0,42$ & 0,08 & $0,10-0,30$ & 0,07 \\
\hline
\end{tabular}

\section{Parâmetros temporais}

A tabela 4 e a figura 6, indicam que a duração média das frases emitidas pelos animais dos 3 grupos esteve de acordo com as descrições de Arvola (1974), Berryman (1976) e Coulon (1982) (Tabela 3). Apesar disso, cobaias apresentaram menor número de pulsos e durações médias de pulsos e intervalos entre eles mais longos do que os dois grupos de preás (os valores destes parâmetros, nos três grupos, estão dentro dos limites indicados na literatura, Tabela 3). Em conseqüência, a taxa (número de pulsos por segundo) nas cobaias foi menor do que nas duas populações de preás. Os preás de ltu foram os que apresentaram, em média e no valor máximo, maior número de pulsos e taxa maior.

\section{Parâmetros relativos à freqüência}

Drrs de cobaias apresentaram, em média, menor número de elementos de freqüência visíveis nos sonogramas, com alguns casos nos quais não haviam componentes de freqüência acima da faixa da fundamental (Tabela $4 \mathrm{e}$ Figura 7). Em todas as emissões de preás (Münster e Itu) pudemos identificar 
pelo menos um elemento de freqüência acima da faixa máxima da fundamental.

A faixa da fundamental (da margem inferior à superior) dos preás de Itu, situou-se em freqüências menores do que as ocupadas, nos outros dois grupos (bem semelhantes entre si), pela faixa da fundamental. Cobaias e preás de Münster apresentaram valores médios muito próximos para estes parâmetros e sua freqüência dominante ocupou a faixa de freqüência da fundamental. $A$ freqüência dominante, no caso dos preás de Itu não coincidia com a faixa da fundamental e ocupava freqüências inferiores às de cobaias e preás de Münster (Tabela 4 e Figura 7).

Nenhum drr ultrapassou 2,5Khz, o limite de freqüência na qual os sonogramas foram gerados. A freqüência máxima foi maior nos preás de Münster, vindo em seguida as cobaias (Berryman registrou drrs de até 1,7 Khz - tabela 3).

As medidas de freqüência dominante e os valores das intensidades dominantes tomadas por pulso não revelaram um padrão de distribuição de energia dentro da frase, ou seja, não havia uma variação regular destes parâmetros de um pulso para outro.

\section{ANÁLISE DE VARIÂNCIA}

A análise de variância univariada revelou diferenças significativas entre osgrupos em 9 dos 10 parâmetros analisados: número de pulsos por frase $\left(F_{(2,32)}=5,6 ; p<0,01\right)$, duração dos pulsos $\left(F_{(2,32)}=36,9 ; p<0,001\right)$, duração dos intervalos entre pulsos $\left(\mathrm{F}_{(2,32)}=19,5\right.$; $\left.\mathrm{p}<0,001\right)$, taxa $\left(\mathrm{F}_{(2,32)}=\right.$ $48,2 ; p<0,001)$; freqüência mínima $\left(F_{(2,32)}=22,1 ; p<0,001\right)$ e máxima $\left(F_{(2,32)}=\right.$ $36,3 ; p<0,001)$ da fundamental, número de elementos de freqüência $\left(F_{(2,32)}<\right.$ $6,9 ; p<0,01)$, freqüência máxima $\left(F_{(2,31)}=9,0 ; p<0,001\right)$ e freqüência dominante $\left(\mathrm{F}_{(2,32)}=6,8 ; \mathrm{p}<0,01\right)$. Apenas a duração das frases não foi significativamente diferente entre os 3 grupos $\left(F_{(2,32)}=0,815 ; p>0,05\right)$.

Os resultados das comparações post hoc (Teste de Tukey) são apresentados na Tabela 5. Cobaias e preás de ltu é que mais se diferenciaram: diferiram entre si em todos os parâmetros, menos na freqüência 
máxima e no número de elementos de freqüência acima da fundamental. Também houve diferenças entre as cobais e os preás de Münster: na duração dos pulsos e dos intervalos entre eles e na taxa, no número de elementos de freqüência e na freqüência máxima. Os dois grupos de preás diferiram apenas na freqüência mínima e máxima da fundamental e na freqüência máxima da frase.

TABela 5. Comparações dois a dois, pelo teste de Tukey, dos parâmetros do $d r r$, em cobaias, preás de Münster e preás de Itu. Asteríscos indicam uma diferença significativa entre grupos $(p<0,01)$.

\begin{tabular}{|c|c|c|c|}
\hline Parâmetros & & & \\
\hline acústicos & & Cobaias & Itu \\
\hline \multirow{2}{*}{ duração da frase } & Münster & 0,452 & 0,979 \\
\hline & Itu & 0,670 & \\
\hline \multirow[t]{2}{*}{ número de pulsos } & Münster & 0,092 & 0,391 \\
\hline & Itu & $0,008^{*}$ & \\
\hline \multirow[t]{2}{*}{ duração dos pulsos } & Münster & $0,000^{*}$ & 0,237 \\
\hline & Itu & $0,000^{*}$ & \\
\hline \multirow[t]{2}{*}{ intervalo entre pulsos } & Münster & $0,000^{*}$ & 0,998 \\
\hline & Itu & $0,000^{*}$ & \\
\hline \multirow[t]{2}{*}{$\operatorname{taxa}$} & Münster & $0,000^{*}$ & 0,047 \\
\hline & Itu & $0,000^{*}$ & \\
\hline \multirow[t]{2}{*}{ freqüência mínima da fundamental } & Münster & 0,188 & $0,000^{*}$ \\
\hline & Itu & $0,000^{*}$ & \\
\hline \multirow{2}{*}{ freqüência máxima da fundamental } & Münster & 0,986 & $0,000^{*}$ \\
\hline & Itu & $0,000^{*}$ & \\
\hline \multirow[t]{2}{*}{ número de elementos freqüência } & Münster & $0,003^{*}$ & 0,831 \\
\hline & Itu & 0,044 & \\
\hline \multirow[t]{2}{*}{ freqüência máxima } & Münster & $0,009^{*}$ & $0,001^{*}$ \\
\hline & Itu & 0,496 & \\
\hline \multirow{2}{*}{ freqüência dominante } & Münster & 0,713 & 0,019 \\
\hline & Itu & $0,003^{*}$ & \\
\hline
\end{tabular}


Uma análise de variância com dois fatores, sexo (machos, $n=11$; fêmeas, $n=10$ ) x grupo (cobaias, $n=10$; Münster, $n=11$ ), não revelou diferenças sexuais $(p>0,05)$ mas indicou diferenças significativas entre cobaias e preás de Münster quanto à duração da frase $\left(F_{(1,21)}=25,06 ; p<0,01\right)$ e à taxa $\left(F_{(1,21)}\right.$ $=31,97 ; p<0,01)$.

\section{ANÁLISE DISCRIMINANTE}

Todos os parâmetros acústicos foram levados em conta neste teste. A análise indicou serem a taxa e a freqüência máxima da faixa da fundamental as variáveis relevantes para a reclassificação das emissões nos seus grupos originais (cobaias, preás de Itu ou preás de Münster). $\mathrm{Na} 1^{\mathrm{a}}$ etapa da análise, a taxa foi distinguida, uma vez sendo a variável com o menor valor de lambda. $\mathrm{Na} 2^{\mathrm{a}}$ etapa, a freqüência máxima da fundamental foi incluída por ser o parâmetro cuja entrada na análise levava a uma diminuição do valor anterior de lambda, correspondente à taxa. A Tabela 6 mostra os valores do $\mathrm{F}$ univariado $\mathrm{e}$ lambda de Willks dos parâmetros que entraram na análise a cada etapa.

TABela 6. Valores de $\mathrm{F}$ e lambdas de Wilks das variáveis que entraram na análise em cada etapa.

\begin{tabular}{|l|l|r|r|}
\hline Etapas & & \multicolumn{1}{c|}{$\begin{array}{c}\text { F to } \\
\text { Remove }\end{array}$} & \multicolumn{1}{c|}{$\begin{array}{c}\text { Wilks' } \\
\text { Lambda }\end{array}$} \\
\hline 1 & taxa & 46,669 & \\
\hline 2 & taxa & 28,049 & 0,283 \\
\hline & fudmax & 22,884 & 0,249 \\
\hline
\end{tabular}

Foram duas as funções discriminantes criadas pela análise (número de grupos menos 1). A função 1, apresentou porcentagem de variância (calculada a partir do índice Eigenvalue) bem maior do que a função 2, o que indica o seu valor para a discriminação; a contribuição relativa dos dois parâmetros para cada função é dada pelo valor absoluto de seu coeficiente; esses valores são altos e próximos um do outro (Tabela 7). 
TABELA 7. Eigenvalue, porcentagem de variância e correlação canônica das 2 funções discriminantes geradas pela análise. Estes valores relacionam-se positivamente com o poder explicativo da variância de cada função

\begin{tabular}{|l|r|r|r|r|}
\hline Função & Eigenvalue & \multicolumn{1}{c|}{$\begin{array}{c}\text { \% de } \\
\text { variâcia }\end{array}$} & $\begin{array}{c}\text { \% } \\
\text { acumulada }\end{array}$ & $\begin{array}{c}\text { Correlação } \\
\text { canônica }\end{array}$ \\
\hline 1 & 3,950 & 79,1 & 79,1 & 0,893 \\
\hline 2 & 1,047 & 20,9 & 100,0 & 0,715 \\
\hline
\end{tabular}

Classificação das emissões nos grupos. A análise discriminante permitiu distribuir os chamados individuais pelos três grupos de animais. A Tabela 8 mostra que todas as emissões de preás de Itu foram classificadas corretamente (isto é, incluídas no grupo dos preás de ltu); que as emissões das cobaias e dos preás de Münster foram quase todas classificadas corretamente (houve apenas uma emissão, em cada caso, atribuída a um grupo diferente do qual pertenciam de fato). Ao todo, foram classificadas corretamente $94,3 \%$ das emissões.

TABELA 8. Freqüência e porcentagem de chamados drrs atribuídos ao grupo ao qual pertencia o emissor (Análise discriminante).

\begin{tabular}{|c|c|c|c|c|c|}
\hline & \multirow{2}{*}{$\begin{array}{l}\text { Classificação } \\
\text { resultante da } \\
\text { análise }\end{array}$} & \multicolumn{3}{|c|}{ Classificação inicial dos grupos } & \multirow{2}{*}{$\begin{array}{c}\text { Total de } \\
\text { casos }\end{array}$} \\
\hline & & Münster & Cobaias & Itu & \\
\hline $\mathrm{n}$ de & Münster & 12 & 1 & 0 & 13 \\
\hline casos & Cobaias & 1 & 13 & 0 & 14 \\
\hline & Itu & 0 & 0 & 8 & 8 \\
\hline$\%$ de & Münster & 92,3 & 7,7 & 0 & 100 \\
\hline casos & Cobaias & 7,1 & 92,9 & 0 & 100 \\
\hline & Itu & 0 & 0 & 100 & 100 \\
\hline
\end{tabular}

A Figura 8 mostra a distribuição dos chamados de acordo com as duas funções discriminantes geradas pela análise. A figura apresenta a distribuição dos casos (cada vocalização) em torno do centróide do grupo (valor central 
calculado pela análise a partir dos coeficientes individuais de cada grupo) e indica se há sobreposição de casos.



FIGURA 8. Distribuição dos coeficientes calculados pela análise discriminante para cada chamado de acordo com as funções 1 e 2 .

CONTEXTO DE EMISSÃO E FUNÇÃO

A observação dos animais durante os episódios de emissão de $d r r$ confirma que, em ambas as espécies, o chamado tem uma função defensiva. No preá, como na cobaia, o drr aparece diante de mudanças no ambiente, principalmente estímulos auditivos, mas também pode ser eliciado por fatores sociais, como a aproximação de outro indivíduo. Provoca nos outros animais do grupo uma postura de alerta (descrita em Rood, 1972; Messias, 1995), ou uma reação de congelamento (freezing) ou ainda fuga.

Como na cobaia (Arvola, 1974; observação pessoal), a emissão de $d r r$ por um preá pode ser acompanhada por emissão semelhante de outro animal 
do grupo. Os preás, tanto de Münster como de Itu, emitem geralmente uma sequência de drrs, mesmo que o estímulo eliciador não se repita, o que raramente acontece na cobaia (Arvola, 1974; Berryman, 1976 e Coulon, 1982 descrevem o drr na cobaia como emissão singular que não acontece em surtos, a menos que um novo estímulo esteja presente).

Preás respondem com a vocalização $d r r$ a uma gama maior de estímulos. Nos grupos de preás, o drr foi o chamado mais freqüentemente emitido, tanto nas colônias quanto nas sessões de formação de pares. Barulhos mais constantes e graves (como motor de carro em deslocamento, avião) causam reação menor do que ruídos agudos e repentinos/instantâneos (chave, campainha) e do que a aproximação de pessoas (barulho de passos no corredor) e vozes. Após a montagem do equipamento para gravação no cativeiro externo em Itu, que causava sempre a fuga dos animais para os esconderijos, um dos indivíduos saia de sua toca (no grupo 1 o macho era geralmente o primeiro a sair, Tabela 2) e, numa posição de alerta, emitia uma seqüência de drrs. Aos poucos, os outros animais iam retomando suas atividades, mas qualquer barulho ou movimento do experimentador causava imobilidade e drrs, ou fuga, dependendo da intensidade do estímulo.

Nas sessões de formação de pares, preás de Münster e de Itu permaneciam mais tempo em imobilidade do que as cobaias, podendo exibir a posição de alerta durante toda a sessão, e emitiam seqüências longas de drrs mesmo na aparente ausência de estímulos externos. A retirada da colônia, o transporte, a caixa não-familiar e a presença de um animal não-familiar pareciam ser nos preás, estímulos suficientes para a eliciação do drr. Quando os preás exploravam a caixa, locomovendo-se lentamente e erguendo-se sobre as patas traseiras, o drr era sempre a vocalização que acompanhava a exploração. Na cobaia, ao contrário, o chut (Tabela 1) era a vocalização mais utilizada, propiciada pelo abandono rápido da postura de alerta e pelo surgimento de respostas de exploração social ou do ambiente.

Em Münster, a manipulação de fêmeas no período final da gestação geralmente evocava drrs. Duas fêmeas jovens, irmãs, colocadas numa caixa com um macho adulto, emitiam drrs toda vez que eram manipuladas até que 
fossem recolocadas nas suas caixas. A manipulação de outros animais que não fêmeas grávidas não eliciou o drr. Em Itu não fizemos sessões de manipulação dos animais mas observamos emissão de drr de um macho e, depois, de uma fêmea adultos enquanto estavam sendo segurados na mão para a marcação do corpo com descolorante. A manipulação de cobaias também produzia drr mas as emissões mais freqüentes eram chuts e chutters, gritos e uma variação do purr cuja intonação e duração parecia acompanhar o movimento dos dedos sobre o dorso do animal (Tabela 1).

Em cobaias, não era qualquer ruído que eliciava o drr. $\mathrm{O}$ drr era registrado apenas diante de estalos de dedos, ou, poucas vezes, quando um barulho ocorria perto dos animais, interrompendo a exploração social. A emissão de drrs, por pelo menos 1 indivíduo de qualquer sexo, era imediata. Jovens e filhotes também respondiam vocalmente a esse tipo de estímulo.

O estalo de dedos nas salas das colônias dos preás em Münster podia eliciar a emissão de $d r r$, quando não ocasionava primeiro a fuga dos animais, e freqüentemente resultava ne emissão do chamado "song" (Tabela 1).

\section{Dıscussão}

Semelhanças na função e na estrutura global dos drrs. Processos seletivos que se supõe terem atuado durante a domesticação, ou durante a diferenciação de populações selvagens de preás, não afetaram o drr em dois aspectos fundamentais: (1) na sua função: em ambas as populações de preás assim como nas cobaias o drr constitui um chamado de alerta de curta distância que evoca, em outros indivíduos, a postura de alerta, o congelamento ou a fuga; (2) na sua estrutura acústica básica: nas duas populações de preás e na cobaia o drr está composto de unidades praticamente idênticas, repetidas em intervalos iguais de tempo, com pouca ou nenhuma modulação de freqüência e de amplitude entre os pulsos. Estas semelhanças não eliminam contudo a relevância das diferenças de pormenor sobre as quais pode ter-se exercido a pressão evolutiva e que podem ter a ver com um distanciamento entre espécies e populações. Nesta discussão, consideraremos ambas as 
populações de preás como selvagens, não no sentido de que os indivíduos não tenham sofrido a influência das condições de cativeiro em que foram mantidos (principalmente os de Münster), mas no sentido de semelhança genética com a estirpe original, na natureza. Os preás de Itu foram, em sua maioria, capturados no campo e mantidos por um tempo relativamente curto em cativeiro; os de Münster, apesar de descendentes de algumas gerações de biotério, e eles-próprios criados neste contexto, não nos parece que devam ser tomados como tendo sofrido um processo seletivo de domesticação.

Diferenças interespecíficas. A análise sonográfica revelou diferenças significativas entre Cavia porcellus e $C$. aperea (a opção por um $p=0,01$ é razoavelmente exigente e coloca em terreno mais firme a inferência de diferenças interespecíficas). As cobaias diferiram de ambos os grupos de preás (Münster e Itu) em parâmetros temporais dos chamados - duração dos pulsos, intervalo entre pulsos e taxa de emissão - sem que houvesse discrepância na duração das frases. As cobaias têm drrs de elementos mais longos e espaçados entre si do que os animais selvagens, mas mantêm igual a duração global dos chamados.

Houve diferenças específicas entre cobaias e preás de Münster (número de elementos de freqüência e freqüência máxima, ambos mais altos em Münster) e entre cobaias e preás de Itu (número de pulsos, maior em Itu; freqüência máxima da fundamental, mais baixa em Itu; e freqüência dominante, também mais baixa em Itu).

Miller e Gottlieb (1981) também encontraram mudanças significativas em caracteres acústicos (freqüência) decorrentes de domesticação: notaram que a freqüência dominante do chamado de alerta era mais grave numa espécie domesticada de patos em relação à espécie selvagem, e atribuiram a diferença ao fato de os patos domesticados terem maior tamanho corporal. O tamanho corporal não poderia explicar as diferenças nas características de freqüência dos drrs de cobaias e preás, uma vez que estas são maiores do que aqueles e produzem chamados menos graves. Desforges e Wood-gush (1976) já haviam descrito mudanças na qualidade acústica do assobio de corte da mesma 
espécie de patos observada por Miller e Gottlieb (1981) quando comparados com a linhagem domesticada Aylesbury: a seqüência de movimentos durante a corte era a mesma mas o assobio que acompanha esse comportamento da linhagem domesticada era menos modulado e tinha intensidade menor.

Tomamos aquí, como hipótese de trabalho, por ser a mais plausível e a mais cautelosa, a de considerar como produtos do processo de domesticação apenas os caracteres em que as cobaias diferem tanto da população de Münster como da população de Itu, ou seja, os parâmetros temporais. As diferenças específicas entre cobaias e preás de Münster, e entre cobaias e preás de Itu decorreriam, de acordo com esta hipótese, da diferenciação entre as populações selvagens provenientes de pressões seletivas na natureza.

Parece até certo ponto compreensível que a domesticação atue preferencialmente em aspectos temporais dos chamados (duração e taxa). Mudanças deste tipo, intuitivamente, implicam numa menor transformação dos programas neurais geradores, uma vez que não afetam a qualidade acústica do som, mas sim, sua padronização temporal. Miller e Gottlieb (1981) encontraram em patos domesticados (Anas platyrynchos) chamados de alerta maternos com notas mais curtas do que em patos selvagens. Ruiz-

Miranda et al. (1999), comparando 2 populações de micos leões (uma nascida em cativeiro, a outra selvagem) também encontraram diferenças nos padrões temporais: os indivíduos em cativeiro (evidentemente, não poderiam ser tomados como domesticados) emitiam chamados longos com menor freqüência do que os indivíduos da população selvagem, mas a diferença pode ter a ver apenas com mudança dos limiares de reação a estímulos externos.

A duração da frase como caracter dependente do contexto. $\mathrm{O}$ fato de a duração da frase ter se mantido constante, entre cobaias e preás, merece ser discutido. Talvez não seja esta duração um caracter relevante em termos de sistemática, uma vez que parece depender do contexto ambiental em que o drr é evocado. Embora não tenhamos tentado nenhuma quantificação (teria sido necessário, primeiro, categorizar ou controlar experimentalmente a natureza, duração e intensidade dos eventos eliciadores; nas condições em que 
efetuamos as gravações, era muitas vezes difícil identificá-los) pareceu-nos que a duração tinha a ver com a natureza destes eventos e com outras causas imediatas como o comportamento ou postura do animal no momento da emissão. De qualquer modo, a variabilidade dos registros era grande.

Há vários relatos, na literatura, que comprovam efeitos do estado do animal ou da natureza do estímulo, sobre a qualidade de sua vocalização. Newman e Goedeking (1992), por exemplo, citam observações de Rowell (1962) e Rowell e Hinde (1962) sobre as vocalizações roucas da espécie de primata Macaca mulatta emitidas em encontros agonísticos. Estas vocalizações apresentavam gradações, principalmente no número de unidades acústicas e na duração da emissão, supostamente dependentes de diferenças por mudanças no estado interno dos indivíduos.

Mudanças nas condições de eliciação. As diferenças interespecíficas não se restringem às características sonográficas do $d r r$, abrangem as condições de sua eliciação. O princípio geral é este: as cobaias reagem menos do que os preás às mudanças ambientais geradoras de comportamento defensivo. Esta diferença poderia ser atribuída ao efeito do contexto de domesticação: na ausência da pressão de predação, variantes genéticos de cobaias que reagem de modo menos pronto e menos generalizado a estímulos novos, e potencialmente ameaçadores, teriam uma chance de se difundirem pela população. Do ponto de vista da causação imediata, a diferença entre cobaias e preás poderia remontar a (1) uma elevação do limiar de desencadeamento do comportamento defensivo: estímulos mais intensos seriam necessários para evocar respostas defensivas e, entre elas, a vocalização $d r r$; (2) a um aumento de seletividade quanto aos estímulos capazes de eliciar respostas defensivas e (3) a uma diminuição da propensão para a produção de sequências de drrs, na ausência de estimulação ambiental imediata.

A redução do comportamento defensivo através da domesticação já foi relatada (Smith, 1972; Desforges e Wood-gush, 1975; Butler, 1980; Blanchard et al., 1986; Price, 1998). Nossos resultados confirmam os dados comparativos de Künzl e Sachser (1999) com preás e cobaias. 
Diferenças entre as populações de preás. As diferenças na estrutura sonográfica do $d r r$, entre preás de Münster e de ltu - centradas em caracteres de freqüência, com menores freqüências mínima e máxima da fundamental e a freqüência máxima da frase em preás de Itu - apontam para uma diferenciação destas populações, até certo ponto surpreendente se partirmos da idéia do $d r r$ como caracter típico da espécie.

Os preás de Itu emitiram chamados mais graves do que os de Münster (a faixa da fundamental do drr ocupa freqüências inferiores, a freqüência dominante está mais baixa também, embora o resultado esteja apenas próximo da significância estatística). Não se pode, por enquanto, saber se esta diferença constitui uma diferença de comunicação propriamente dita, isto é, se ela reflete um reconhecimento e uma reação diferenciais, os preás de uma população reagindo mais prontamente ou preferencialmente aos chamados de indivíduos de mesma origem do que a indivíduos da outra.

Não se pode atinar quais os fatores seletivos ambientais que poderiam ter levado à seleção de freqüências. Haveria que se saber algo a respeito dos predadores de preás existentes num e noutro habitat (na Argentina, província de Buenos Aires, de onde provieram os preás de Münster, e de Itu, estado de São Paulo, onde foram capturados os preás brasileiros) e a respeito da sensibilidade destes eventuais predadores à dimensão de freqüência contida em chamados drr. Também ter-se-ia que supor uma predação diferencial de acordo com a freqüência. Também haveria que se examinar se fatores ambientais, num habitat e noutro, facilitam diferencialmente a transmissão pelo ambiente de chamados drrs mais agudos ou mais graves.

O reconhecimento das diferenças nos chamados. A localização de diferenças na qualidade acústica de chamados não é suficiente para garantir que estas diferenças possuem um sentido enquanto mensagem, enquanto elemento de comunicação social. Variações em parâmetros como faixa de freqüência ou nas características temporais dos sinais podem ser reconhecidos (Newman e Goedking, 1992; Hailman e Ficken, 1996). Evans (1993) apresentou a filhotes de patos playbacks com alteração sintética da freqüência dominante. Apesar 
de a latência da resposta ser menor frente a playbacks alterados e diminuir proporcionalmente com o grau de alteração desse parâmetro, o fato de os patinhos ainda responderem ao chamado de alerta materno sugere que outros parâmetros acústicos (como a modulação de freqüência e as caracterísitcas temporais) também estejam em jogo no reconhecimento do chamado como sendo o de um coespecífico (Evans, 1993).

O chamado "song". Tanto preás como cobaias, emitem outro chamado de alerta, também rítmico mas de freqüência e intensidade muito maiores do que o drr. Rood (1972) o descreveu como um sinal do qual seria difícil de idenficar o emissor. É o "song" que pudemos registrar em preás de Münster e que foi observado em cobaias por Arvola (1974), Berryman (1976) e Coulon (1982). Os estímulos eliciadores deste chamado em preás parecem os mesmos que eliciam o drr, mas em intensidade maior ou a uma distância menor dos animais: estímulos visuais e sonoros, alterações do meio social, resposta a emissão de outros animais, mesmo em grupos separados. A emissão de "song" por cobaias é muito rara, comprovando sua menor sensibilidade a alterações do ambiente. 


\section{4}

PURR: UM CHAMADO DE CORTE

A corte em cobaias envolve uma seqüência de movimentos e emissões vocais: o macho cheira a região ano-genital da fêmea, circula em torno do corpo dela numa locomoção lenta com o corpo esticado e trêmulo, pára em sua frente e movimenta a parte traseira do corpo levantando uma perna por vez: é a rumba, exibição de corte descrita por King (1956) e citada por muitos autores que estudaram diferentes aspectos em cobaias (Rood, 1972; Arvola; 1974; Heinemann, 1974; Berryman, 1976; Coulon, 1982; Sachser, 1986 e 1999). Rood (1972) e Messias (1995) observaram a rumba em preás adultos durante cortejo de fêmeas.

O purr é o chamado de corte que sempre acompanha a rumba e cujo ritmo de emissão acompanha o ritmo da rumba (quando direcionados à fêmeas receptivas ou fêmeas desconhecidas, a rumba e o purr apresentam ritmo mais acelerado indicativo do grau de excitação do macho; Coulon, 1982). Outros chamados podem estar presentes durante a corte, emitidos por fêmea nãoreceptiva frente às aproximações do macho e por outras fêmeas e filhotes presentes na caixa (chutters e whines - Berryman, 1976), pelos machos simultaneamente à emissão purr (grito agudo de excitação - Coulon, 1982). Berryman (1976) afirma que fêmeas receptivas também rumbam e emitem purr enquanto exibem posição de lordose e durante monta e cópula.

Mais do que um sinal de corte, o purr é um chamado indicativo da excitação do animal. Quando colocado em grupo novo, um macho rumba e emite purr enquanto investiga com o nariz a região posterior dos outros animais da caixa, até que identifique um macho e substitui o purr pelo entrechoque de 
incisivos (Arvola, 1974); animais de ambos o sexos emitem purrs quando excitados por algum estímulo do meio, como alimento muito apreciado (Coulon, 1982); fêmeas separadas de seus filhotes por um dia emitem purr quando eles são recolocados em sua caixa, da mesma forma que eles emitem purr enquanto a investigam e procuram pela teta (Arvola, 1974; Coulon, 1982); o purr pode ser emitido pelo macho vencedor de uma luta (Coulon, 1982) ou durante a luta intercalado com o entrechoque de incisivos (Berryman, 1976); animais criados na mão emitem purr quando pegos pelo tratador, tocados no dorso e alimentados (Berryman, 1976).

Filhotes de ambos os sexos emitem purr enquanto se aproximam da mãe e procuram pela teta (Arvola, 1974; Berryman, 1976; Coulon, 1982). Neste caso, a emissão é, para Coulon (1982), uma variação do grito rítmico sexual, denominada grito rítmico de amamentação, emitido por filhotes de ambos os sexos até os 14 dias de vida; nessa idade deixa de ser produzido pelas fêmeas e sofre mudanças ontogenéticas nos machos, que os emitem quando próximos às irmãs e durante a procura pela teta da mãe, quando podem começar a exibir a rumba.

\section{INFORMAÇÕES PRÉVIAS A RESPEITO DA ESTRUTURA ACÚSTICA DO PURR DA COBAIA}

O raio X feito por Arvola (1974) no momento da emissão revela que o purr é um chamado nasal emitido com boca fechada e sem movimentos de estruturas na cavidade bucal. As cavidades ressonantes são as nasais, a garganta e provavelmente a traquéia. A anestesia da língua não altera a emissão do purr.

Assim como o chamado de alerta, o purr é formado por unidades breves idênticas, repetidas em intervalos iguais formando uma frase (Arvola, 1974; Berryman, 1976; Coulon, 1982). Também apresenta uma faixa de freqüência fundamental e elementos de freqüência acima dessa faixa. Segundo Arvola (1974), as diferenças entre os dois chamados estão na duração da frase (purré mais longo e ocorre, em geral, em surtos com várias frases de durações variadas; Arvola afirma que o drr não é repetido sem recorrência do estímulo 
eliciador), na ritmicidade (o purr tem ritmo mais lento) e na freqüência da fundamental (menor no purr).

A tabela 9 mostra os parâmetros acústicos de purrs emitido por cobaias, segundo Arvola (1974), Berryman (1976) e Coulon (1982). Os valores apresentados correspondem aos limites máximos e mínimos obtidos para cada parâmetro. Os valores nos parênteses em algumas células representam os valores mais comumente obtidos. Na coluna com a descrição de Coulon separamos o grito de amamentação, que é mais curto e menos grave, do grito sexual, apesar do ritmo ser o mesmo.

A diferença entre os autores nos parâmetros duração da frase e número de pulsos por frase pode ser compreendida pelo fato de que a emissão muitas vezes apresenta-se fragmentada. Quando perturbado por estímulos externos ou mesmo evitação da fêmea ou interferência de outro animal, o macho interrompe a emissão e pode retomar em seguida formando seqüências pequenas de purr separadas por intervalo muito curto seguido de nova seqüência. Esses intervalos curtos podem ser considerados pelos autores como uma frase fragmentada (Arvola, 1974) ou como frases independentes que compõem um surto (Berryman, 1976; o intervalo entre purrs num surto é de aproximadamente 0,06 segundos).

Machos jovens emitem frases mais fragmentadas do que machos adultos e fêmeas receptivas evocam purrs longos e menos fragmentados (Arvola, 1974; Coulon 1982). Purrs emitidos por fêmeas geralmente contém mais elementos de freqüência do que a emissão de machos (Berryman, 1976).

Ao contrário de Arvola (1974) que descreve os componentes de freqüência como fracos e difíceis de serem separados no sonograma, Berryman (1976) os descreve como intensos mas intercalados com ruído nas freqüências maiores (ou seja, nos últimos elementos de freqüência). Segundo a autora a freqüência mínima dos pulsos pode aumentar na segunda metade da frase. 
TABELA 9. Parâmetros acústicos do chamado de corte (purr) de cobaias (Berryman; 1976; Arvola, 1974; Coulon, 1982). A faixa de freqüência apresentada é a faixa da fundamental.

\begin{tabular}{|l|c|c|c|c|}
\hline & & & \multicolumn{2}{c|}{ Coulon } \\
\cline { 4 - 5 } & Berryman & Arvola & amamentação & sexual \\
\hline ritmo (pulsos/s) & & $13-16$ & $14-16$ & $14-16$ \\
\hline duração dos pulsos (s) & $0,025-0,06$ & $0,01-0,04$ & & \\
\hline intervalo entre pulsos (s) & $0,02-0,06$ & $0,03-0,07$ & & \\
\hline número de pulsos & $7-81$ & $20-30$ & $5-23$ & \\
\hline duração da frase (s) & $0,525-3,6$ & $0,2-5,5(1-2)$ & $0,3-1,3$ & $15-20$ \\
\hline faixa de freqüência (Hz) & $200-750$ & $170-500(250-300)$ & 450 & 200 \\
\hline freqüência máxima (Hz) & 2000 & 2000 & & \\
\hline número de harmônicos & $1-7$ & $1-5$ & & muitos \\
\hline
\end{tabular}

\section{Resultados}

\section{ANÁLISE DESCRITIVA}

A Figura 9 apresenta sonogramas de purrs emitidos por cobaias e preás de Münster. As médias dos 11 parâmetros acústicos das 8 emissões de cada grupo estão representados graficamente nas Figuras 10, 11 (parâmetros temporais relativos ao surto e medidas tomadas da frase, respectivamente) e 12 (parâmetros de freqüência). Os valores mínimo e máximo (limites) e o desvio padrão (dp) de cada variável estão indicados na Tabela 10. 




FIgURA 9. Sonograma representativo do chamado purr emitido por um macho cobaia. Nesse caso, a emissão teve apenas uma frase que durou cerca de 5 segundos. 


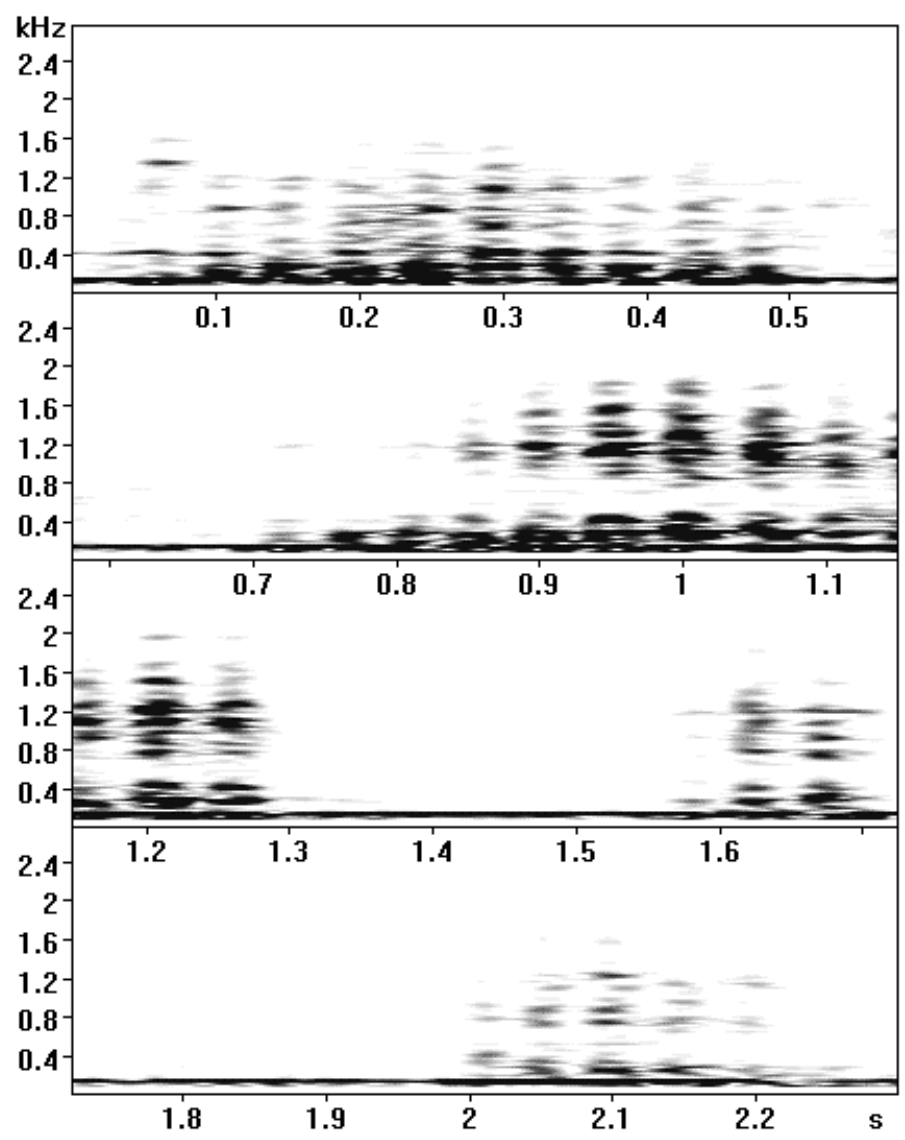

FIGURA 10. Sonograma representativo do chamado purr emitido por um macho preá do cativeiro de Münster. $O$ animal emitiu 4 frases curtas, sendo as duas últimas formadas por número menor de pulsos (3 e 5 pulsos, respectivamente). 



Figura 11: Médias dos parâmetros temporais tomados de surtos do chamado de corte, purr, emitidos por cobaias e preás de Münster. 

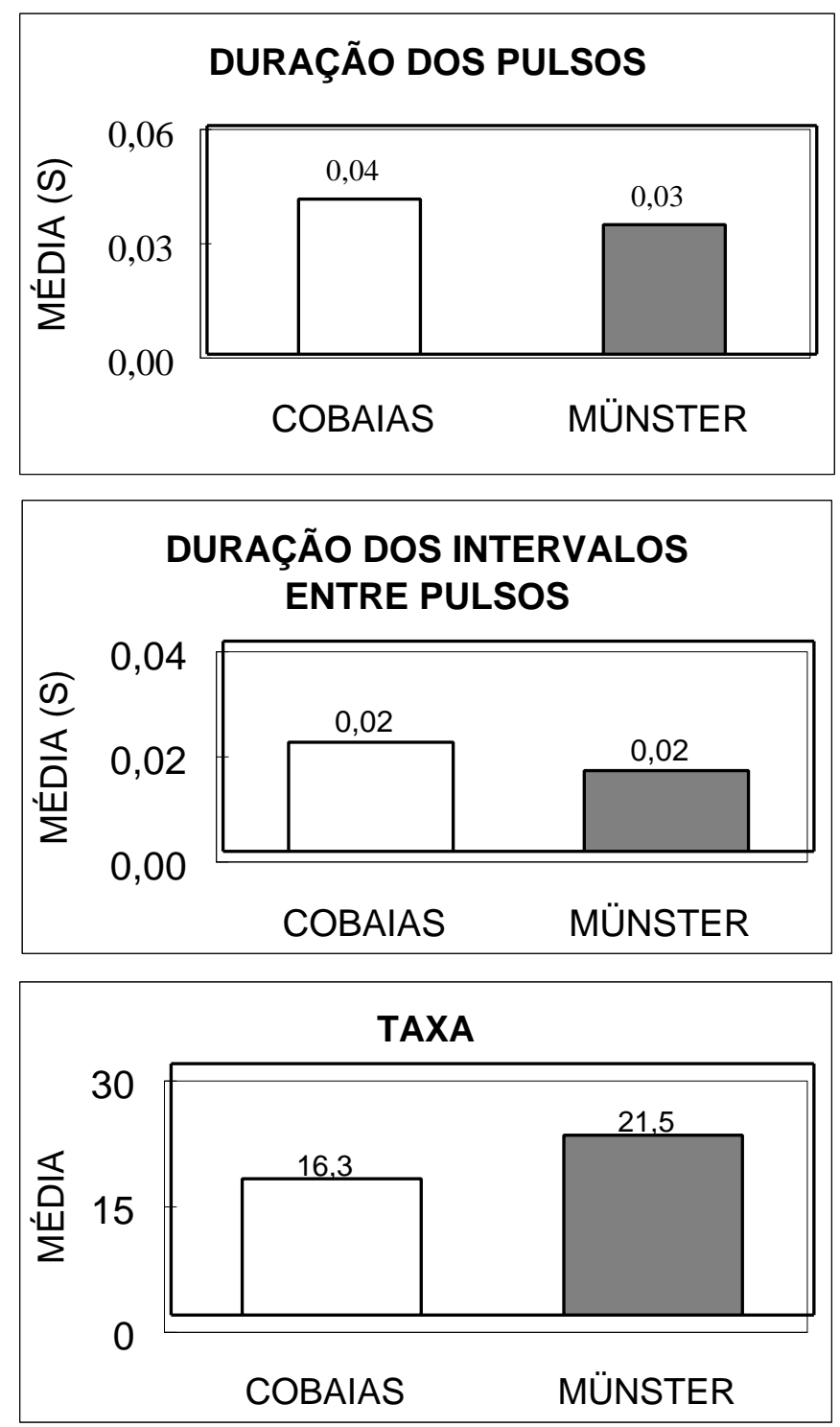

Figura 12. Médias dos parâmetros temporais tomados medidos nas frases do chamado de corte, purr, emitidos por cobaias e preás de Münster. 

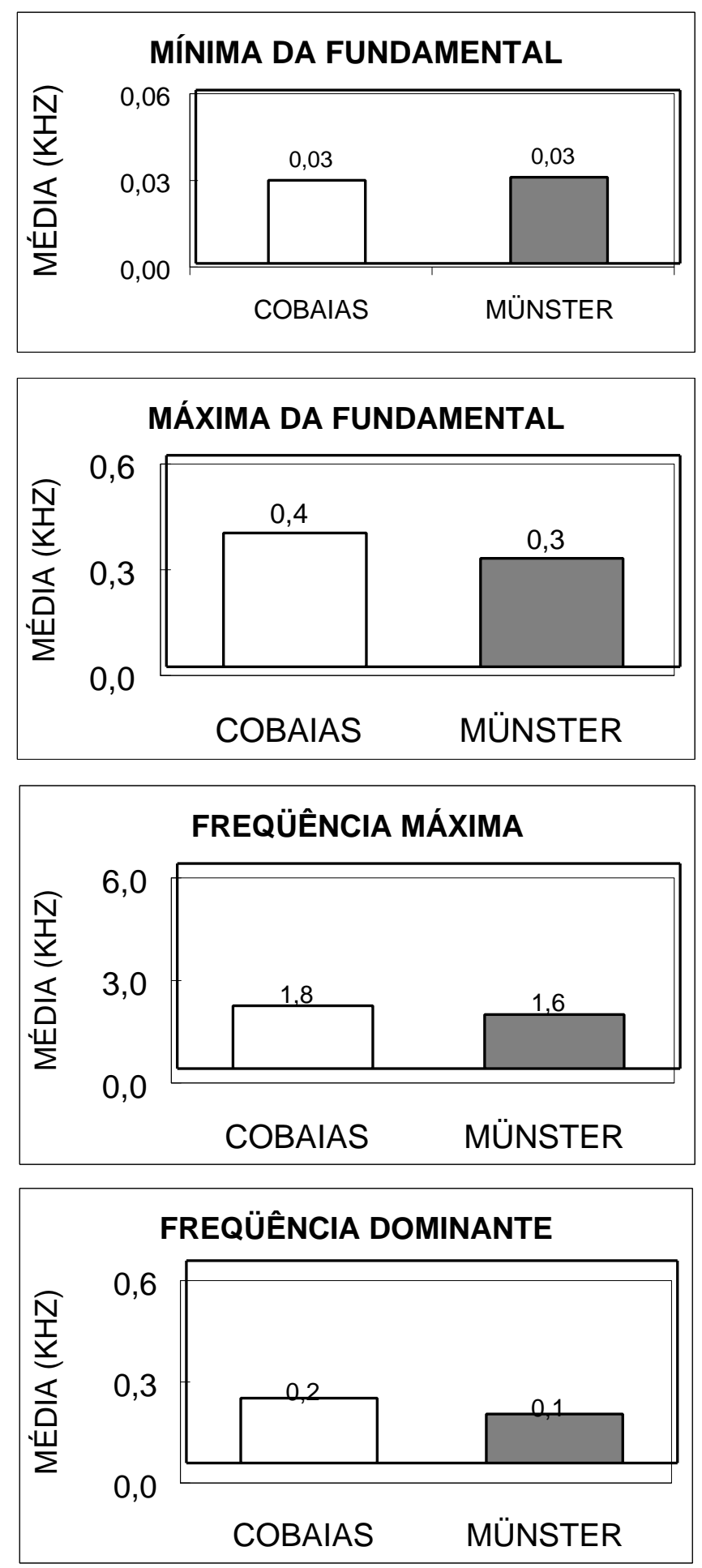

FIgURA 13. Médias dos 4 parâmetros acústicos de feqüência medidos nas emissões dos chamados de corte, purr, de cobaias e preás de Münster. 
TABELA 10. Valores mínimo e máximo (limites) e desvio padrão (dp) dos parâmetros 
acústicos de purrs emitidos por cobaias e preás de Münster

\begin{tabular}{|l|r|r|r|r|}
\hline \multirow{2}{*}{$\begin{array}{c}\text { Parâmetros } \\
\text { acústicos }\end{array}$} & \multicolumn{2}{c|}{ Cobaias } & \multicolumn{2}{c|}{ Münster } \\
\cline { 2 - 5 } & min-max & dp & min-max & dp \\
\hline duracão do surto (s) & $2,45-9,94$ & 2,41 & $1,38-8,54$ & 2,65 \\
\hline número de frases por surto & $1,20-3,20$ & 0,75 & $1,00-4,80$ & 1,33 \\
\hline duração da frase (s) & $1,22-8,30$ & 2,26 & $0,51-3,69$ & 1,01 \\
\hline intervalo entre frases (s) & $0,21-0,51$ & 0,12 & $0,11-0,49$ & 0,14 \\
\hline duração dos pulsos (s) & $0,04-0,05$ & 0,00 & $0,03-0,04$ & 0,00 \\
\hline intervalo entre pulsos (s) & $0,02-0,03$ & 0,00 & $0,01-0,02$ & 0,00 \\
\hline taxa (pulso/s) & $13,98-18,62$ & 1,33 & $18,29-25,99$ & 2,57 \\
\hline freqüência mínima da fundamental (kHz) & $0,02-0,05$ & 0,01 & $0,02-0,05$ & 0,01 \\
\hline freqüência máxima da fundamental (kHz) & $0,31-0,46$ & 0,05 & $0,27-0,39$ & 0,04 \\
\hline freqüência máxima $(\mathrm{kHz})$ & $1,22-2,34$ & 0,43 & $1,07-2,29$ & 0,44 \\
\hline freqüência dominante $(\mathrm{kHz})$ & $0,13-0,28$ & 0,05 & $0,06-0,25$ & 0,06 \\
\hline
\end{tabular}

\section{Parâmetros temporais}

A Tabela 10 e a Figura 11 nos mostram que, em média, cobaias apresentaram surtos, frases e intervalos entre frases mais longos do que preás de Münster, apesar de o número médio de frases (purrs) por surtos não variar muito entre esses dois grupos. Esse resultado deve refletir, na verdade, uma maior fragmentação das emissões dos preás de Münster (para Arvola, 1974 as frases de um surto são consideradas fragmentações de uma única frase, enquanto para Berryman, 1976, elas são frases independentes).

A duração e os intervalos entre pulsos dos purrs de cobaias também são mais longos, em média, e consequentemente têm taxa (número de pulsos por segundo) menor do que o dos preás (Figura 12). A duração dos pulsos dos dois grupos estão de acordo com os resultados encontrados por Arvola (1974) e Berryman (1976) em cobaias (Tabela 9). 
Parâmetros relativos à freqüência

Com exceção da freqüência mínima, todos os parâmetros de freqüência medidos em purrs de cobaias foram, em média, superiores aos valores encontrados nas emissões de preás de Münster (Figura 13).

\section{ANÁLISE DE VARIÂNCIA}

O resultado da análise univariada, que comparou parâmetros acústicos de purrs emitidos por cobaias e preás de Münster revelou diferença significativa $(p<0,01)$ em 4 dos 11 parâmetros analisados: duração dos pulsos $\left(F_{(1,14)}=15,2\right.$; $p=0,002)$, duração dos intervalos entre pulsos $\left(F_{(1,14)}=8,5 ; p=0,011\right)$, taxa $\left(F_{(1,14)}\right.$ $=25,6 ; p=0,000)$; freqüência máxima da fundamental $\left(F_{(1,14)}=10,7 ; p=0,006\right)$.

\section{ANÁLISE DISCRIMINANTE}

Dos 11 parâmetros acústicos submetidos à análise discriminante, o parâmetro 'taxa' foi suficiente para discriminar entre os grupos ( $F=26,47$ e lambda de Wilks $=0,33$ ). Após esta etapa, nenhum outro parâmetro diminuía o valor do lambda da 'taxa' (assumindo probabilidade de F menor ou igual a 0.01).

Como só tínhamos 2 grupos, a análise criou apenas uma função discriminante (número de grupos menos 1). A Tabela 11 apresenta a porcentagem de variância (que indica a sua força discriminativa) e a contribuição do parâmetro 'taxa' para a função 1.

TABELA 11. Eigenvalue, porcentagem de variância e correlação canônica das 2 funções discriminantes geradas pela análise.

\begin{tabular}{|c|c|c|c|}
\hline & & $\%$ de & Correlação \\
\cline { 4 - 4 } Função & Eigenvalue & Variância & Canônica \\
\hline 1,000 & 2,036 & 100 & 0,819 \\
\hline
\end{tabular}

Classificação das emissões nos grupos. A porcentagem de de classificações corretas aos grupos originais foi de $87,5 \%$. Os 8 casos de 
cobaias foram corretamente classificados no grupo cobaia, enquanto 2 dos 8 casos de preás de Münster foram errôneamente classificados com sendo emiisões de cobaias.

\section{CONTEXTO DE EMISSÃO E FUNÇÃO}

Das observações feitas com os 3 grupos dec animais (cobaias, preás de Itu e de Münster) podemos dizer que todas as rumbas observadas foram acompanhadas do purr.

Cobaias e preás machos emitem purrs durante o cortejo de fêmeas receptivas ou não, em direção a animais estranhos introduzidos em suas caixas ou em caixas-teste (como descrito por Arvola, 1974, o purr acompanha a fase de investigação social sendo substituído pelo entrechoque de incisivos quando o animal investigado é um macho), durante interação com jovem macho, ao retornarem às suas caixas após retirada para limpeza (neste caso todos os animais parecem excitados e exploram a caixa emitindo chuts Berryman, 1976 - e purr).

Cobaias de ambos os sexos, desde muito jovens (segunda semana de vida), podem emitir purr quando são tocados no dorso. Em preás isso não acontecia; a resposta deles era freezing ou tentativa de fuga, as vezes, acompanhada de gritos agudos (scream ou squeal de Berryman, 1976). Preás cortejam menos (Künzl e Sachser, 1999) e, portanto, emitem purr menos freqüentemente do que cobaias. Além disto, os machos cobaias parecem mais insistentes no cortejo das fêmeas não-receptivas do que machos preás.

Filhotes de ambos os sexos tanto em preás como em cobaias, emitem uma variante do purr quando se aproximam da teta da mãe para mamar. Jovens cobaias rumbam e emitem purrs mais freqüentemente e menos direcionados do que machos adultos.

Nos grupos de cobaias e preás de Münster formados apenas por fêmeas (tabela 2) podia acontecer de a fêmea dominante do grupo se comportar de maneira semelhante aos machos dominantes dos outros grupos (famílias ou jovens machos): investigava a região ano-genital, exibia rumba e emitia purrs a indivíduos não-familiares introduzidos em suas caixas (essa interação poderia 
ser substituída por exibições de evitação ou agressão dependendo do sexo do "invasor").

Durante sessões de formação de pares de machos de preás ambos os animais emitiam prrs durante investigação. Porém, estabelecida a dominância de um sobre o outro o entrechoque de incisivos emitidos por ambos era intercalado, no macho dominante, com purrs (Berryman, 1976 observou isto em cobaias).

\section{Dıscussão}

Nossas observações mostram serem muito semelhantes as seqüências básicas de comportamento de corte nas cobaias e nos preás, sejam eles da amostra de Münster ou de Itu, e corroboram a idéia geral de que a padronização das atividades básicas é menos suscetível de mudanças decorrentes da domesticação que os aspectos motivacionais e de prontidão (Hale, 1962). Patos domesticados, do mesmo jeito, apenas diferem dos selvagens em aspectos quantitativos (Desforges e Wood-Gush, 1976).

A primeira diferença importante entre cobaias e preás tem a ver com a freqüência maior com que as cobaias emitem o comportamento de corte. Nossos dados confirmam, neste ponto, estudos prévios. Künzl e Sachser (1999) observaram que machos de cobaias exibem mais rumbas e emitem significativamente mais prrs do que machos preás mantidos nas mesmas condições de cativeiro. A partir da comparação do comportamento de preás em condições naturais e cobaias em condições de cativeiro, Rood (1972) também verificou ser maior nas cobaias a taxa da rumba.

A segunda diferença se localiza nas características temporais do sinal acústico, o purr. O purr das cobaias tem um pulso mais longo, maiores intervalos entre pulsos e uma taxa menor do que o dos preás. O aumento de duração da frase e do intervalo entre frases, que a média indica, não se revelou, contudo, significativo. É interessante notar que estas diferenças apoiadas pela análise discriminante, que indica ser a taxa o caracter mais relevante para a distinção das populações - são semelhantes às diferenças 
temporais encontradas na análise comparativa dos drrs. Tanto no caso do purr como no do drr, as cobaias são mais "demoradas" do que os preás, sem no entanto encompridar o chamado como um todo. A semelhança dos efeitos da domesticação sobre chamados de alerta e de corte poderia ser atribuída a uma seleção independente de cada um deste tipos de vocalização. É tentador imaginar, ao contrário, que refletem uma mudança a nível mais profundo, num módulo da produção de chamados rítmicos relacionado com a duração de elementos e com a densidade temporal de sua emissão. A este módulo de geração acústica corresponderia um módulo de recepção, sintonizado, seletivamente, em caraterísticas temporais.

A queda da taxa também é interessante por se manifestar em chamados que envolvem uma identidade emissor-receptor diferente. $O$ chamado de alerta é produzido e recebido tanto por fêmeas como por machos; o chamado de corte é produzido apenas por machos e decodificado apenas por fêmeas. Uma mudança análoga em atos comunicativos tão diferentes sugere que a existência de constraints ou calibrações sensório-motoras semelhantes em ambos os sexos e válidas para o conjunto dos chamados. Caberia verificar se, em outras vocalizações que não 0 drr e o purr se mantém a distinção entre cobaias acusticamente "demoradas" e preás acusticamente "rápidos".

A terceira diferença entre as duas espécies se manifestou no domínio das freqüências: a freqüência máxima da fundamental foi significativamente mais alta nos purrs de cobaias do que nos de preás (de maneira geral, embora sem significância estatística, os parâmetros de freqüência dos chamados foram superiores em cobaias do que preás). Não há paralelismo, neste caso, com o drr (Figura 7) e, dentro de nossa hipótese, a freqüência não faria parte do módulo básico. A freqüência máxima e a freqüência máxima da fundamental do drr são mais baixas para cobaias do que para preás de Münster.

Não sabemos se a freqüência máxima da fundamental constitui uma característica discriminável pela fêmea de cobaia ou de preá. Poderia ser uma diferença acústica irrelevante do ponto de vista da comunicação e do processo de corte. 
São conhecidas diferenças na biologia reprodutiva das cobaias e de preás: a duração do ciclo estral é menor, o período de gestação e o tamanho das ninhadas são maiores na espécie domesticada (Rood, 1972; Weir, 1974). A estas diferenças, típicas do processo de domesticação (Price, 1984; 1998), nossos resultados acrescentam outras, ligadas ao sinal acústico produzido durante a corte. Torna-se uma questão de extremo interesse evolutivo, saber se as diferenças temporais e de freqüência entre os purrs de cobaias e de preás atuam como barreiras reprodutivas. Um preá macho que emitisse purr como uma cobaia teria menos chances de acasalar-se com uma preá fêmea mas acesso facilitado a uma fêmea de cobaia. $O$ mesmo poderia ser esperado de uma cobaia que emitisse purr como preá, mas a simetria nos efeitos interespecíficos não necessariamente deveria imperar.

A maior fragmentação temporal dos surtos emitidos por preás de Münster poderia significar, como os resultados a respeito do drr, que, apesar das gerações criadas em biotério, esses animais continuam sensíveis ao caráter de perigo das mudanças ambientais. Também poderia ser atribuída às respostas de esquivas das fêmeas, mais freqüentes e vigorosas do que no caso das fêmeas de cobaias (Kunzl e Sachser, 1999). 


\section{5}

\section{DISCUSSÃO GERAL E CONCLUSÕES}

A domesticação é mais do que o ajustamento dos indivíduos de uma espécie à presença do ser humano e às condições de cativeiro. Price (1998) segue a colocação do próprio Darwin (1979), e a define como "um processo evolutivo que envolve a adaptação genotípica dos animais ao ambiente do cativeiro" (grifo nosso). Populações cativas, menores do que as que vivem na natureza, mantidas isoladas do fluxo gênico proveniente de outras populações, sem alternativa a não ser submeter-se ao regime de seleção, intencional ou não, a que os submetem os seres humanos, estão em condições mais do que propícias para sofrer alterações genéticas (Futuyma, 1986). Representam, em contraposição à seleção natural, uma seleção artificial, de acordo com critérios nem sempre explicitáveis acompanhada do que pode ainda haver de seleção natural no cativeiro. A comparação entre uma espécie domesticada e a espécie que poderia ser a espécie ancestral ou uma espécie próxima desta, tem relevância por lançar luz sobre aspectos do processo de transformação genotípica.

Não há porque esperar que sejam necessariamente idênticos os efeitos do processo de domesticação nas diversas espécies domesticadas: além das propensões naturais de cada espécie, de que os espécimes não desistem ao serem trazidos para o convívio com o ser humano, há variações no tipo de prática reprodutiva. Efeitos comumente encontrados são: redução de agressividade, principalmente em relação ao ser humano (Connor, 1975; Price, 1984), menor reação a alterações ambientais e ao contato com o ser humano (Smith, 1972; Butler, 1980; Price, 1984; Blanchard e col., 1986), maior 
freqüência e prontidão de exibição de comportamentos sexuais (Price, 1984) no setor comportamental, além de alterações morfológicas, como o aumento do tamanho corporal e de estruturas internas (Weir, 1974; Miller e Gottlieb, 1981) e fisiológicas como o aumento do período de gestação e do tamanho das ninhadas e diminuição da duração do ciclo estral (Rood, 1972; Weir, 1974).

A tolerância maior a coespecíficos e a plasticidade social também são traços comumente encontrados em animais domesticados. $O$ camundongo selvagem Mus musculus muda em condições semi-naturais a sua estrutura social, baseada numa territorialidade agressiva, numa estrutura baseada em hierarquias de dominância, se o espaço de cativeiro for reduzido e se mantiver a densidade populacional (Butler, 1980). Cobaias mantêm a homeostase do grupo frente a um aumento populacional formando sub-unidades em que um macho forma laços com várias fêmeas e defende seu território em relação às invasões de outros machos (Sachser, 1985; 1998).

A comunicação vocal, como qualquer outro caracter comportamental, pode sofrer mudanças devido à domesticação. Apesar de sua importância (sem que entre nesta colocação nosso viés, compreensível, em prol do estudo de vocalizações), este aspecto não tem recebido muita atenção dos pesquisadores. O exemplo padrão, que temos usado repetidamente nesta dissertação, é o dos patos da linhagem comercial Aylesbury que emitem assobios (grunt-whistle) em menor número do que os patos selvagens, mas, em compensação, aumentam os chamados de baixas freqüências, low-grunt (Desforges e Wood-Gush, 1976). Noutra linhagem de patos domesticados (Pekin), os efeitos da domesticação atuaram sobre a estrutura acústica do chamado de alerta materno, diminuindo a freqüência dominante e a duração da nota (Miller e Gottlieb, 1981).

Price (1998), num texto excelente sobre genética comportamental e o domesticação, arrola dificuldades, metodológicas e conceituais, na abordagem em que se pretende comparar uma amostra domesticada à amostra selvagem. Cabe verificar de quais o presente estudo escapa e quais ainda permanecem.

(1) A origem ancestral de um certo animal doméstico não é clara, ou já foi extinta a espécie selvagem correspondente. Nenhuma destas condições se 
aplica ao presente estudo: $C$. aperea, a estirpe selvagem, claramente está relacionada a C. porcellus, a ponto de alguns autores, entre os quais Sachser (1998) as colocarem como populações da mesma espécie. A vantagem dos caviídeos como modelo está justamente na possibilidade de levar adiante comparações no cativeiro mantendo-se ambas as espécies em condições ambientais semelhantes; ou entre cativeiro (cobaias) e natureza (preás).

(2) Mesmo quando populações ancestrais estão disponíveis, não se pode garantir que tenham permanecido estáticas desde o início do processo de domesticação. Não há, de fato, como garantir que os preás usados em nossa pesquisa não tenham sofrido mudanças evolutivas posteriores à época em que alguns dentre eles começaram a ser usados como animais de estimação. As diferenças entre preás de Münster e de Itu é uma prova de que houve divergência posterior ao início da domesticação, ou então, de que existiam, na época inicial, em diversas regiões, populações de preás comportamentalmente (e geneticamente) divergentes. Isto nos leva ao ponto seguinte.

(3) Por causa da variação geográfica, nenhuma das populações selecionadas para estudo representa de maneira adequada a diversidade genética presente na população. Não há como saber qual das duas populações observadas aqui, Münster (proveniente de um estoque argentino; Itu) é mais próxima da população ancestral. Pelo menos, nosso estudo tem o mérito de ter indicado a possibilidade de diferenças dentro da espécie de preás. A pesquisa sugere que seriam interessantes levantamentos geográficos sistemáticos capazes de fornecer um mapeamento dos preás e de desvendar, de maneira mais exaustiva, a sua gama de variabilidade comportamental. O repertório vocal poderia ser rastreado de região para região.

De qualquer maneira, como já indicado, tomamos como critério provisório o de considerar como indicativas dos efeitos da domesticação as diferenças que se mantêm as mesmas, na comparação cobaia $x$ preás de Münster e na comparação cobaia $x$ preá de Itu. É importante notar que as diferenças obtidas através destas duas comparações foram maiores (no número de parâmetros diferentes) do que as diferenças obtidas através da 
comparação preás de Münster x preá de Itu. Isso significa que a variação interespecífica foi maior do que a interpopulacional.

Além disso, enquanto as diferenças entre cobaias e preás eram predominantemente diferenças temporais (duração de pulso ou intervalo, taxa); as diferenças entre as populações de preás, no drr, eram relacionadas principalmente a aspectos da freqüência do sinal acústico. Uma possível inferência (pelo menos a mais cautelosa) é supor que tenha a domesticação atuado principalmente em aspectos temporais das respostas de alerta e de corte.

(4) Em que medida é representativa a população doméstica estudada ? Em outros termos, em que medida é a amostra utilizada num determinado laboratório (no nosso laboratório da USP) representativa da espécie, da cobaia domesticada em geral ? Diferenças entre estoques de cobaia, de acordo com a proveniência, não são impensáveis, embora não nos pareça que sejam muito marcadas.

(5) A maioria das comparações entre populações selvagens e domésticas são realizadas com animais que se criaram seja na natureza, seja no cativeiro, mas não em ambos os ambientes. Nossas amostras de cobaias provêm de criações de biotério, assim como as amostras de preás de Münster e vários dos animais de Itu. Se isto, de um lado, garante uma homogeneidade ambiental propícia para comparações e se diminui a possibilidade de discrepâncias devidas à experiência dos animais em contextos de criação diferentes; de outro, viesa as observações a favor do contexto de biotério, não sabemos se haveria diferenças nas vocalizações dos preás, se registradas in situ, na Argentina ou no Brasil.

Nossas análises confirmam a proximidade de $C$. porcellus e $C$. aperea, na dimensão da comunicação vocal. Os chamados rítmicos drr e purr têm o mesmo padrão geral, são emitidos nos mesmos contextos e evocam respostas semelhantes. Isto não significa necessariamente que drr, purr e o comportamento em geral apresente uma resistência especial à mudança genotípica. Talvez signifique apenas que não houve, no ambiente de cativeiro, uma seleção sistemática que se aplicasse a eventuais variantes da estrutura 
básica dos chamados. Os chamados de alerta e de corte não se modificaram de forma qualitativa por não haver, no cativeiro, pressão seletiva para tal.

A presença do chamado de alerta song no repertório das cobaias, apesar de rara, tem relevância para a hipótese de preservação das características vocais básicas. Indica que não houve, com a domesticação, perda ou surgimento de novos sinais, mas um aproveitamento dos sinais básicos em transformações restritas. Seguindo a caracterização dos chamados de alerta de Bradbury e Vehrencamp (1998), tanto o song quanto o drr são chamados de alerta que transmitem informações acerca da presença de predadores ou de um rival, mas com características acústicas peculiares e poder de evocar respostas diferentes (o song corresponde a notas de assobio repetidas rapidamente e de freqüência entre 1,5 e 6,0 kHz). Parece-nos que o song evoca resposta de dispersão (flee alarm call), enquanto o drr evoca a tomada de postura de atenção frente a algum estímulo diferente mas que ainda não é reconhecido como perigo eminente (assembly alarm call ou alert alarm call; Bradbury e Vehrencamp, 1998).

Uma outra questão de interpretação é a da possível influência da experiência passada nas diferenças entre espécies. Domesticação também é produto de "eventos de desenvolvimento induzidos pelo ambiente e repetidos a cada geração (Price, 1998). Poderiam os filhotes de preá e os de cobaia adquirir aspectos de sua vocalização por ouvir as de adultos ? Para testar esta possibilidade, estamos planejando um estudo de criação cruzada, filhotes de preás sendo criados por mães cobaias e filhotes de cobaia por mães preás. Uma diferenciação dos chamados, nos filhotes adotivos em relação aos chamados de irmãos criados pela mãe genética poderiam levar a insights preciosos sobre a ontogênese da comunicação nos caviideos.

De dentro da semelhança estrutural básica é que surgem variações significativas entre $C$. porcellus e $C$. aperea e entre as populações de $C$. aperea:

(1) em parâmetros temporais: a duração dos pulsos e o intervalo entre pulsos do purr e do drr emitidos pelas cobaias são mais longos do que os emitidos por preás. 
(2) em parâmetros de freqüência: a cobaia apresenta drrs e purrs mais agudos (freqüência mínima maior no caso de durr purr,: faixa de freqüência da fundamental mais larga) do que os apresentados pelo preá.

(3) na energia (intensidade/volume): a cobaia apresenta drrs e purrs mais intensos do que os do preá.

Outra diferença relevante ocorre, no $d r r$, não nas características do próprio chamado, mas na seletividade e nos limiares de reação a eventos ambientais: os preás são mais reativos a eventos repentinos e emitem drrs diante de um maior número de estímulos do que as cobaias. Os preás de Münster também emitem o song muito mais freqüentemente (nos preás de Itu essa emissão era ouvida apenas quando o tratador se aproximava do cativeiro externo).

As diferenças nos parâmetros de freqüência e na energia tornam o drre o purr da cobaia mais ostensivos do que os do preá. Era difícil, quando estávamos observando diretamente os animais, localizar o emissor de um $d r r$ de um preá, no meio de outros preás. Como o drr e o purr são chamados de curta distância, emitidos para possível influência sobre animais próximos, parece fazer sentido que o préa os tenha mais graves e de menor intensidade, dificultando sua detecção por predadores, mas não pelos coespecíficos.

No ambiente natural, o preá tem alta taxa de predação (Matthias Asher, comunicação pessoal: $50 \%$ dos animais acompanhados com rádio-colar foram predados durante os 6 meses de trabalho no campus da USP em Ribeirão Preto). Segundo Cassini e Galante (1992), forragear em grupo parece ser uma adaptação da espécie ao binômio valor nutritivo/risco de predação, uma vez que aumenta a probabilidade de que um ou mais animais do grupo detectem predadores terrestres e alertem os outros através de chamados vocais.

Somente houve diferença entre os chamados de alerta de preás de Münster e de Itu quanto aos parâmetros de freqüência (faixa da fundamental e freqüência máxima). O contexto de emissão, a freqüência de resposta e a gama de estímulos eliciadores do drr não diferenciaram estas populações de mesma espécie. 
Qual a origem da mudanças nas vocalizações de alerta e de corte em animais domesticados ? Parece-nos pouco provável que tenham decorrido de uma seleção direta pelo ser humano, do mesmo tipo que a que produziu as raças de cães. Em primeiro lugar, os chamados de alerta e de corte não são discriminados com acuidade pelo ouvido humano (especialmente quando não se dispõe de ajuda sonográfica); em segundo lugar, não há motivo muito claro para que um criador reproduza seletivamente os espécimes com chamados mais agudos ou com taxa mais espaçada.

A seleção poderia ser indireta, isto é, decorrer do papel que outro caracter (associado às vocalizações) tivesse nas vicissitudes seletivas da reprodução em cativeiro. Por exemplo, se a altura do assobio ao tratador fosse um fator que levasse alguns animais (os que tivessem esse assobio mais agudo) a receberem mais alimento e de alcançarem uma maior probabilidade de se reproduzirem, talvez, por fazer parte do mesmo sistema sensório-motor, outras vocalizações como o drr e o purr fossem se tornando mais agudas.

A seleção de caracteres morfológicos ou fisiológicos também poderia embasar um processo indireto de mudança genotípica. (a seleção destes traços gerando efeitos em traços comportamentais, Belayev, 1979 em Grandin e Deesing, 1984). Animais maiores poderiam ter sido selecionados pelos domesticadores, a partir do critério de maior quantidade de carne por peça. Não parece contudo haver uma relação simples entre tamanho do corpo de um preá ou de uma cobaia e o espaçamento dos pulsos num chamado de alerta.

Outros fatores são o relaxamento de seleção natural, por conta da proteção oferecida pelo cativeiro, que faria com que características menos favoráveis fossem mantidas e ganhassem em proporção na população; ou efeitos de deriva genética ou ainda a restrição de variabilidade decorrente do endocruzamento (Price, 1984; 1998). São fatores que podem atuar em conjunto e que é difícil destrinchar, mesmo em condições de laboratório. A descoberta de diferenças no comportamento vocal entre $C$. porcellus e $C$. aperea e entre populações de $C$. aperea, seja lá qual for o fator preciso que as gerou abre caminho para hipóteses bem interessantes a respeito do papel 
destas diferenças, especialmente das que têm a ver com o purr, na manutenção e no fortalecimento de barreiras reprodutivas entre estirpes.

Eisenberg colocou uma pergunta, em 1974, a respeito da origem do rico repertório de chamados das cobaias: seria ele produto da domesticação ? teriam as populações selvagens a mesma variedade de sinais à sua disposição ? Temos agora bases concretas para afirmar que sim, que preás de fato possuem a mesma gama de vocalizações que a espécie domesticada, sem acréscimos nem perdas, conforme seria de se esperar a partir das discussões em torno de domesticação de Hale (1962), Ratner e Boice (1975) e Price (1998). A semelhança entre o repertório vocal das espécies juntamente com os resultados do trabalho de Künzl e Sachser (1999) evidenciam a proximidade filogenética de cobaias e preás.

Mas nossa pesquisa também forneceu uma base para dizer que a domesticação trouxe novidades no modo como a cobaia produz duas de suas mais importantes vocalizações, o drr, de alerta, e o purr, reprodutivo. Embora recente o advento da domesticação - 1.000 a 3.000 anos, segundo Weir (1974); 3.000 a 6.000 anos segundo Heinemann (1974) - houve tempo para que o comportamento vocal da cobaia mudasse significativamente. Os dados sobre a vocalização poderiam ser tomados, junto com outros dados comportamentais, para indicar que C. porcellus e C. aparea entraram, de forma irreversível, num processo de especiação. 


\section{6}

\section{REFERÊNCIAS BIBLIOGRÁFICAS}

Arvola, A. (1974). Vocalizations in the guinea pig Cavia porcellus. Ann. Zool. Fennici, 11, 1-96

Belyaev, D.K, Plyusnina, I.Z e Trut, L.N. (1984). Domestication in the silver fox (Vulpes fulvus desm): changes in the physiological boundaries of the sensitive period of primary socialization. Applied Animal Behaviour Science, 13 , 359-370

Berryman, J.C. (1976). Guinea pig vocalizations: their structure, causation and function. Zeitschrift fur Tierpsychologie, 41, 80-106

Blanchard, R.J; Flannelly, K.J e Blanchard, D.C. (1986). Defensive behaviors of laboratory and wild Rattus norvegicus. Journal of Comparative Psychology, 100, 101-107

Bradbury, J.W e Vehrencamp, S.L. (1998). Cap 17: Costs and constrains on signal evolution. Em: Bradbury, J.W. e Vehrencamp, S.L. Principles of Animal Communication, Sinauer Associations, Canada, 537-570

Brown, C.H, Gomes, R. e Waser, P.M (1995). Old World monkeys vocalizations: adaptations to the local habitat? Animal behavior, 50 , 945961

Butler, R.G. (1980). Population size, social behaviour and dispersal in house mice: a quantitative investigation. Animal Behavior, $\underline{28}, 78-85$

Cassini, M.H e Galante, M.L. (1992). Foraging under predation risk in the wild guinea pig: the effect of vegetation height on habitat utilization. Annales Zoologic Fennici, 29, pp 285-290

Clements, M. (1998). Cap 2: Digital signal acquisition and representation. Em: Hopp, S.L, Owren, M.J. e Evans, C.S. (Eds) Animal Acoustic Communication: Sound Analysis and Research Methods. SpringerVerlag Berlin Heidelberg, pp 27-55 
Connor, J.L. (1975). Genetic mecanisms controlling the domestication of a wild house mouse population (Mus muscullus L.) Journal of Comparative and Physiological Psychology, $\underline{89}$ (2), 118-130

Coulon, J. (1982). La communication acoustique du cobaye domestique comparaison avec quelques rongeurs. Journal de Psychologie, 01, 55-78

Desforges, M. F. e Wood-Gush, D.G.M. (1976). Behavioral comparison of Aylesbury and mallard ducks: sexual behaviour. Animal Behaviour, 24, 391-397

Dwyer, C.M; McLean, K.A.; Deans, L.A; Chirnside, J.; Calvert, S.K e Lawrence, A.B. (1998). Vocalisations between mother and young in sheep: effects of breed and maternal experience. Applied Animal Behaviour Science, $\underline{58}, 105-119$

Eisenberg, J.F. (1974). The function and motivational basis of Histricomorphs vocalizations. Symposium of the Zoological Society of London, 34, 211247

Elowson, A.M. e Snowdon, C.T. (1994). Pygmy marmosets, Cebuella pygmaea, modify vocal struture in response to changed social environment. Animal Behaviour, 47, 1267-1277

Elowson, A.M. e Snowdon, C.T. e Sweet, C.J. (1992). Ontogeny of trill and Jcall vocalization in the pygmy marmoset, Cebuella pymaea. Animal Behaviour, $\underline{43}$, 703-715

Evans, C.S. (1993). Recognition of contentment call spectral characteristics by mallard ducklings: evidence for a consistent perceptual process. Animal Behaviour, 45, 1071-1082

Faure, M.J e Mills, A.D. (1998). Cap 8: Improving the adaptability of animals by selection. Em: T. Grandin (Ed) Genetics and the Behavior of Domestic Animals.. San Diego, California, pp 235-264

Futuyma, D.J. (1986). Cap. 7: Seleção sobre caracteres poligênicos. In: Futuyma, D.J. Biologia Evolutiva, Ribeirão Preto, São Paulo, pp 196-223

Futuyma, D.J. (1986). Cap. 8: Especiação. Em: Futuyma, D.J. Biologia Evolutiva, Ribeirão Preto, São Paulo, pp 232-264

Grandin, T e Deesing, M.J (1998). Cap 1: Behavioral Genetics and Animal Science. In: T. Grandin (Ed) Genetics and the Behavior of Domestic Animals.. San Diego, California, pp 1-30

Grier, J.W e Burk, T. (1992). Cap 15: Animal Communication. Em: Biology of Animal Behavior. St Louis. Mosby Year Book, 2th edition 
Gustafsson, M.; Jensen, P.; Jonge, F.H. e Schumman, T. (1999). Domestication effects on foraging strategies in pigs (Sus scrofa). Applied Animal Behaviour Science, $\underline{62}, 305-317$

Hale, E.B. (1962). Cap 2: Domestication and the evolution of behaviour. Em: E.S.E. Hafez (Ed) The Behaviour of Domestic Animals, 1a ed, London, pp 21-54

Hailman, J.P. e Ficken, M.S. (1996). Cap 8: Comparative analysis of vocal repertoires, with reference to chickadees. Em: Kroodsma, D.E. e Miller, E.H. (Eds). Ecology and Evolution of Acoustic Communication in Birds. Cornell University Press, London, pp 136-159

Hauser, M. D. (1989). Ontogenetic changes in the comprehension and production of vervet monkey (Cercopithecus aethiops) vocalizations. Journal of Comparative Psychology, 103 (2), 149-158

Hauser, M. D. (1996). Cap 2: The evolution of communication: historical overview. In: Hauser, M.D. (Ed). The Evolution of Communication. The MIT Press, Massachusetts, pp17-62

Heinemann, D. (1974). Cap. 9: The rodents. Em: Grzimek's, B Animal Life Enciclopedia. New York, van Nortrand Reinhold, pp 421-456

King, J.A. (1956). Social relation of the domestic guinea pig living under seminatural conditions. Ecology, 37, 221-228

Kroodsma, D.E., Vielliard, J.M.E e Stiles, F.G. (1996). Cap 15: Study of bird sounds in the neotropics: urgency and opportunity. Em: Kroodsma, D.E. e Miller, E.H. (Eds). Ecology and Evolution of Acoustic Communication in Birds. Cornell University Press, London, pp 269-280

Künzl, C. e Sachser, N. (1999). The endocrinology of domestication: a comparison between the domestic guinea-pig (Cavia aperea f. porcellus) and its wild ancestor, the cavy (Cavia aperea). Hormones and Behavior, $\underline{35}, 28-37$

Lieblich, A.K., Symmes, D., Newman, J.D e Shapiro, M. (1980). Development of isolation peep in laboratory-breed squirel monkeys. Animal Behavior, $\underline{28}$, $1-9$

Lillehei, R.A. e Snowdon, C.T. (1978). Individual and situational differences in the vocalizations of young stumptail macaques (Macaca arctoides). Behaviour, $\underline{65}, 270-281$

Marler, P. e Hobbett, L. (1975). Individuality in a long-range vocalization of wild chimpanzees. Zeitschrift fur Tierpsychologie, 38, 97-109 
Martens, J. (1996). Vocalizations and speciation of Paleartic birds. Em: Kroodsma, D.E. e Miller, E.H. (Eds). Ecology and Evolution of Acoustic Communication in Birds. Cornell University Press, London, pp 221-238

Marten, K. e Marler, P. (1977) Sound transmission and its significance for animal vocalization, 1. Temperate Habitats., Behavioral Ecology Sociobiology, 2, 271-290

Marten, K.; Quine, D. e Marler, P. (1977) Sound transmission and its significance for animal vocalization, II. Tropical Forest Habitats., Behavioral Ecology Sociobiology, 2, 291-302

McCulloch, S.; Pomeroy, P. P.; Slater, P.J.B. (1999). Individually distinctive pup vocalizations fail to prevent allo-suckling in grey seals. Canadian Journal of Zoology, 77, 716-723.

Messias, M.R. (1995). Biologia comportamental de Cavia aperea (Mammalia: Caviidae) em área aberta no estado de São Paulo. Rio Claro, SP, Universidade Estadual Paulista, Instituto de Biociências. Dissertação de Mestrado, 78p.

Miller, D.B e Gottlieb, G. (1981). Effects of domestication on production and perception of mallard maternal alarm calls: developmental lag in behavioral arousal. Journal of Comparative and Physiological Psychology, 95 (2), 205-219

Monticelli, P.F, Tokumaru, R.S e Ades, C. (1997). Características individuais na vocalização de aflição de filhotes de cobaia doméstica: uma primeira análise. Anais de Etologia 15, 358

Monticelli, P.F, Tokumaru, R.S e Ades, C. (1998). Características individuais na vocalização de aflição de filhotes de cobaia doméstica. Anais do VII Congresso Interno Do Núcleo de Pesquisa em Neurociências e Comportamento, 50 .

Monticelli, P.F e Ades, C (1999). Aspectos acústicos da domesticação: chamados de alerta e de corte no preá (Cavia aperea) e na cobaia $(C$. porcellus). Anais de Etologia 17

Mundinger, P.C. (1970). Vocal imitation and individual recognition of finch calls. Science, $168,480-482$

Mundinger, P.C (1995). Behaviour-genetic analysis of canary song: inter-strain differences in sensory learning and epigenetic rules. Animal Behavior, $\underline{50}, 1491-1511$

Newman, J.D. e Goedeking, P. (1992). Noncategorical vocal communication in primates: the example of common marmosets phee calls. Em: Papousek, $\mathrm{H}$; Jürgens, U; Papousek, M (eds.) Nonverbal vocal communication. pp87-101 
Palombit, R.A. (1992). A preliminary study of vocal communication in wild longtailed macaques (Macaca fascicularis). II Potencial of calls to regulate intragroup spacing. International Journal of Primatology, $\underline{13}$ (2), 183-207

Pinna, M. (1997). Behavioral characters in phylogeny reconstruction. Anais de Etologia, $15,109-124$

Price, E.O (1984). Behavioral aspects of animal domestication. The Quarterly Review of Biology, 59 (1), 1-32

Price, E.O (1998). Cap 2: Behavioral genetics and the process of animal domestication. Em: T. Grandin (Ed) Genetics and the Behavior of domestic animals, San Diego, California, pp 31-66

Provine, R.R; Strawbridge, C.L e Harrison, B.J (1984). Comparative analysis of the development of wing-flapping and flight in the fowl. Developmental Psychobiology, 17 (1), 1-10

Ratner, S.C e Boice, R. (1975). Cap 1: Effects of domestication on Behaviour. Em: E.S.E. Hafez (Ed) The Behaviour of Domestic Animals, 3a ed, London, pp 3-19

Rood, J.P. (1972). Ecological and behavioral comparisons of three genera of Argentina cavies. Animal Behavior Monographs, $\underline{5}$, 1-83

Ruiz-Miranda, C.R; Kleiman, D.G.; Moraes, E. e Grativol, A. (1999). Diferenças da comunicação vocal de micos-leões dourados (Leontopithecus rosalia) nascidos em cativeiro e selvagens. Anais de Etologia 17, 121

Sachser, N. (1986). Different forms of social organization at high and low population densities in guinea pigs. Behaviour, $\underline{97}(\underline{3-4}), 253-272$

Sachser, N. (1998). Of domestic and wild guinea-pigs: studies in sociophysiology, domestication and social evolution. Naturwissenschaften Review Articles, 85, 307-317

Seyfarth, R.M e Cheney, D.L (1986). Vocal development in vervet monkeys. Animal Behaviour, 34, 1640-1658

Smith, R.H (1972). Wildness and domestication in Mus muscullus: a behavioral analysis. Journal of Comparative and Physiological Psychology, 79 (1), 22-29

Smith, H.J., Newman, J.D., Hoffman, H.J. e Fetterly, K. (1982). Statistical discrimination among vocalizations of individual squirrel monkeys (Saimiri sciureus). Folia primatol., 37, 267-279

Snowdon, C.T. e Cleveland, J. (1980). Individual recognition of contact call by pigmy marmosets. Animal Behaviour, 28, 717-727 
Tokumaru, Monticelli e Ades. (1996). Reação de cobaias (Cavia porcellus) a um sinal de alimento. Anais de Etologia 14, 347

Vielliard, J. (1997). O uso de caracteres bioacústicos para avaliações filogenéticas em aves. Anais de Etologia 15 , 93-107

Weir, B.J. (1974). Notes on the origin of the domestic guinea pig. Symp. Zool. Soc. Lond., $\underline{34}$, 437-446

Winter, P., Handley, P., Ploog, D. e Schott, D. (1973). Ontogeny of squirrel monkey calls under normal conditions and under acoustic isolation. Behaviour, 47, 230-239

Wilson, D.E e Reeder, D.M. (1992). Mammal Species of the World: a taxonomic and geographic reference. (Eds), 2a ed. Washington and London, Smithsonian Institution Press. 